\title{
CONTRIBUTION TO THE BRYOFLORA OF AUSTRALIA. VI. THE GENUS COLOLEJEUNEA (SPRUCE) STEPH. (LEJEUNEACEAE, MARCHANTIOPHYTA)
}

\author{
TAMÁs Pócs
}

\begin{abstract}
Thirty-eight species of the genus Cololejeunea (Spruce) Steph. (Lejeuneaceae, Marchantiophyta) are reported for the whole of Australia, more than doubling the number of taxa known since the first account of the Australian members of the genus. Cololejeunea cairnsiana Pócs, Cololejeunea heinari Pócs and Cololejeunea floccosa var. fraseriana Pócs are described as new to science. The records of Cololejeunea diaphana A. Evans, Cololejeunea gottschei (Steph.) Mizut., Cololejeunea longifolia (Mitt.) Benedix ex Mizut. Cololejeunea verrucosa Steph. and Cololejeunea floccosa (Lehm. \& Lindenb.) Steph. var. amoenoides Tixier are new for the continent. Cololejeunea amoena Benedix is treated as a variety of Cololejeunea floccosa. Cololejeunea tortifolia Steph. is synonymized with Cololejeunea microscopica (Taylor) Schiffn. and is excluded from the Australian flora. The name Cololejeunea cambodiana Tixier is validated. A key for the Australian taxa and an analysis of their distribution follow the enumeration of species.
\end{abstract}

Key words: Australia, Cololejeunea, distribution, epiphylls, liverworts, new species, taxonomy

Tamás Pócs, Institute of Biology, Eszterházy Károly University Eger, Pf. 43, H-3301, Hungary; e-mail: colura@upcmail.hu

\section{INTRODUCTION}

The first detailed account of the Australian representatives of the genus Cololejeunea (Spruce) Steph. was given by Thiers (1988), including 17 species, one among them new to science. Pócs (1994) and Pócs and Streimann (1999) reported 7 species new for the continent. The first published checklist of Australian liverworts (McCarthy 2003), which included records from more recent publications, mostly by Australian authors (O'Shea et al. 1997, + 1 species; Bolin \& Henderson 2002, +1 species; Meagher 2003, + 1 species), had already reported 31 species (including the former Aphanolejeunea A. Evans species); later, Pócs and Streimann (2006) added 3, and Renner (2011) added one more species to the list. The present paper enumerates 4 species and one variety new for Australia, describes 2 species and one variety new to science, and includes several new records of rare species. These are the results of my collecting trips during 1999, 2000 and 2001, supported by the Australian Bryological Resources Study Participa- tory Program, during which I was accompanied by local bryologists, among them Heinar Streimann, Andy Cairns, Elizabeth A. Brown, Robert G. Coveny and Christine D. Cargill, as well as my wife, Sarolta Pócs.

The aim of this paper is to summarize the previous records and add all new findings to our knowledge of the genus on the Australian mainland. The records eventually resulted in 38 species with one variety for Australia (excluding the oceanic Lord Howe and Norfolk Islands). Taking into account that the Cololejeunea species find their humid environmental requirements (mostly rainforest habitats) met only in the narrow, forested eastern strip of the continent, this number is quite high and compares well to the 39 species of India (Asthana \& Alam 2013), 63 species of New Guinea (Pócs \& Piippo 2011), 41 species of New Caledonia (Thouvenot et al. 2011), 44 species of Fiji Islands (Pócs 2012, 2015) and 52 species of Madagascar (Marline et al. 2012). 


\section{DESCRIPTION OF NEW TAXA}

\section{Cololejeunea heinari Pócs, sp. nov.}

Figs $1-8$

C. subg. Leptocolea (Spruce) Schiffn.

TyPe MATERIAL: Southern Queensland: Fraser IsLAND (Great Sandy National Park), in Wongoolba Creek $\mathrm{N}$ of the Central Station, at $45 \mathrm{~m}$ alt., $25^{\circ} 28^{\prime} \mathrm{S}$, 153⒊7'E. Date: 17 August 1999. T. Pócs \& H. Streimann 9963/M [ноLотуPE: CANB; ISOTYPE (microslide only): EGR]. Epiphyllous in subtropical rain forest dominated by Syncarpia hillii ('satinay', Myrtaceae) and by Archontophoenix cunninghamiana ('piccabeen palm', Arecaceae), accompanied by Cololejeunea floccosa var. fraseriana, var. nov., Cololejeunea lanciloba Steph., Colura sp., Drepanolejeunea sp. and Siphonolejeunea elegantissima (Steph.) Grolle.

Medium-size epiphyllous plant adhering to the leaf, forming vivid green (turning olive in herbarium) round colonies up to $2 \mathrm{~cm}$ in diameter. Shoot $0.7-1.4 \mathrm{~mm}$ wide, densely branching. Stem 20-40 $\mu \mathrm{m}$ thick, with ventral merophyte of one row of cells, rhizoids richly developed in small bundles below each leaf, short and colorless, often forming secondary rhizoid discs. Leaves cuneate with rounded apex, margin smooth. Marginal lobe cells quadrangular with thinner outer wall, near base elongated parallel to margin, $8-10 \times$ 10-20 $\mu \mathrm{m}$. Other lobe cells isodiametric or elongated hexagonal, with equally thickened walls and small trigones, $15-30 \times 12 \times 25 \mu \mathrm{m}$. Cuticle smooth, in dry state finely striate. Lobule $c a 1 / 6$ of lobe length, triangular, $40 \times 30 \mu \mathrm{m}$, first tooth 1-2 cells long, the second obsolete or sometimes 1 cell long, triangular. Hyaline papilla obovate, $6 \times 4 \mu \mathrm{m}$, at inner proximal base of first tooth. Autoicous. Androecium on short side branches, composed of 2-3 pairs of male bracts, each with 2 antheridia. Gynoecium also on short side branches. Female bracts with subacute lobule reaching 1/3-1/2 length of bract lobe. Perianth $500 \times 400 \mu \mathrm{m}$, subaequal with bracts, cordate, compressed, ventrally bulging, with somewhat auriculate wings with short beak one cell high. Sporophyte and gemmae were not seen.

ETYMology. The new species is named to commemorate the late Heinar Streimann, an outstanding Australian bryologist of Estonian origin, who guided me to the type locality of this species and took part in its collection.

OTHER SPECIMEN SEEN (PARATYPE): southern Queensland, QUEENSLAND: FRASER IsLAND (Great Sandy National Park). Pile Valley along Kingfisher Bay-Eurong road, $55 \mathrm{~m}$ alt., $25^{\circ} 28.4^{\prime} \mathrm{S}, 153^{\circ} 04.3^{\prime} \mathrm{E}$. Epiphyllous in subtropical rain forest formed by the endemic, 50-60 m tall Syncarpia hillii ('satinay') (Myrtaceae), Pócs \& Streimann 9960/S (EGR, G).

There are a few similar, geographically very isolated species that seem to form a more or less natural group within subgenus Leptocolea, characterized by these features: lobe with rounded apex, smooth margin and surface, quadrangular, elongate lobe marginal cells, and flat, cordate perianth with an often free, not connate, apical part. Such species are Cololejeunea tuiwawana Pócs from the Fiji Islands, $C$. amaniensis Pócs and $C$. harrisii Pócs from East Africa, C. lichenyae Porley, Hodgetts \& Wigginton from Malawi, C. magna (Tixier) M. Infante \& Heras and C. tenuiparietata Tixier from Rwanda, and C. iradieri M. Infante \& Heras from West Africa. Cololejeunea lichenyae has two equally large teeth, C. tuiwawana has two obsolete teeth, C. magna has one very long lobule tooth, C. tenuiparietata has very reduced, triangular, unidentate lobuli, and the rest of the species have differently shaped perianths and female bracts (see Fig. 3 of Infante \& Heras 1999).

\section{Cololejeunea floccosa var. fraseriana Pócs,} var. nov. Figs 9-12

\section{C. subg. Taeniolejeunea (Zwickel) Benedix}

TYPE MATERIAL: southern Queensland: Fraser Island (Great Sandy National Park): Pile Valley along Kingfisher Bay-Eurong road, $55 \mathrm{~m}$ alt., $25^{\circ} 28.4^{\prime} \mathrm{S}$, $153^{\circ} 04.3^{\prime}$ E. T. Pócs \& H. Streimann 9960/L (HOLOTYPE: CANB, ISOTYPES EGR, CANB, NSW, BRI, G). Epiphyllous in subtropical rain forest formed by the endemic, 50-60 m tall Syncarpia hillii = 'satinay' (Myrtaceae). It grows together with Cololejeunea tenella Benedix, Cololejeunea heinari sp.n., Cololejeunea lanciloba Steph., Cololejeunea vidliana Tixier, Colura queenslandica B. M. Thiers, Leptolejeunea sp. and Siphomolejeunea elegantissima (Steph.) Grolle.

It differs from Cololejeunea floccosa (Lehm. \& Lindenb. in Lehm.) Schiffn., Consp. Hepat. 

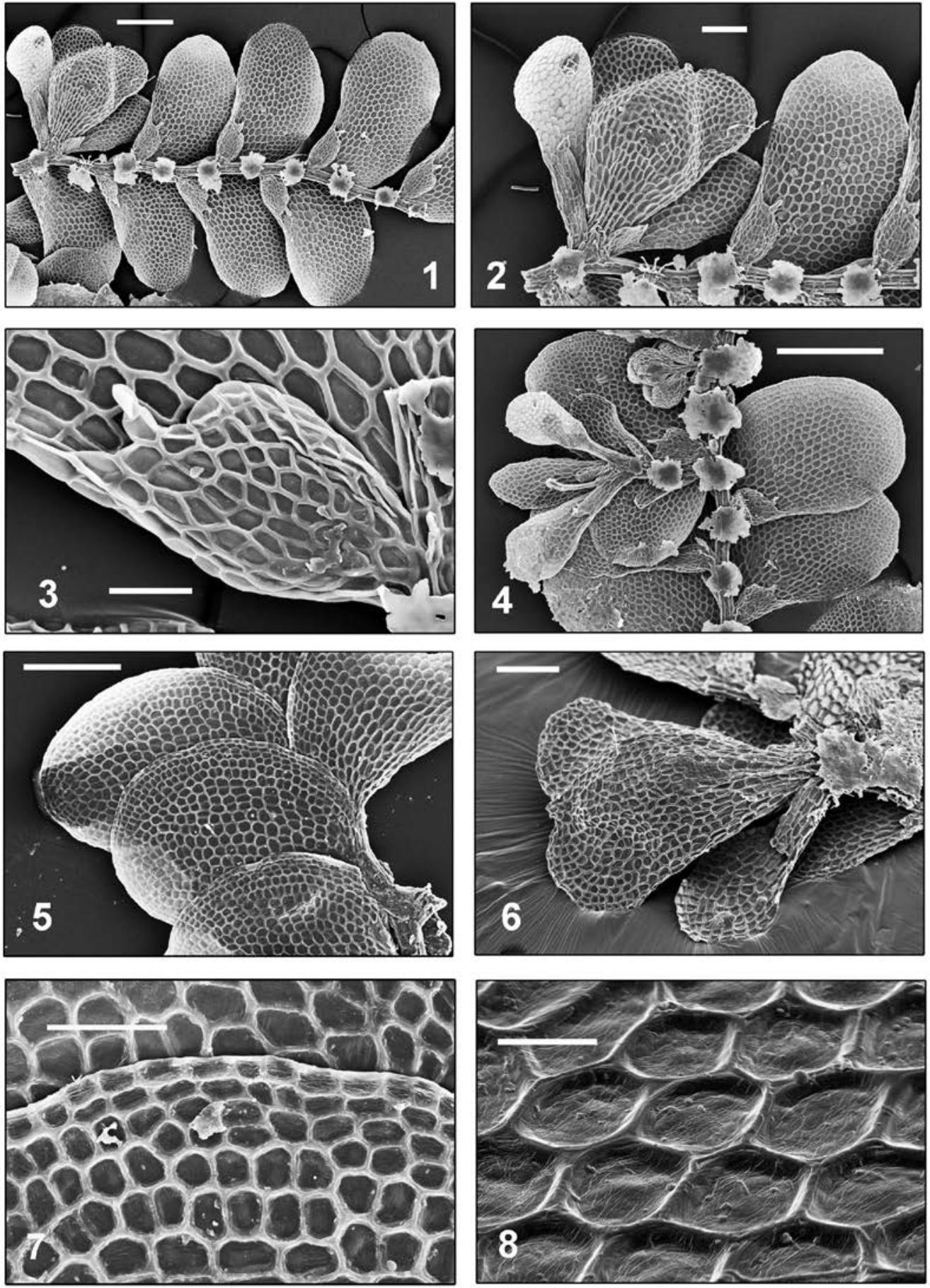

Figs 1-8. Cololejeunea heinari Pócs, sp. nov. 1 - habit, ventral view; $2 \& 6$ - perianth, ventral view; 4 - female bracts, 5 - habit, dorsal view; 7 - lobe marginal cells; 8 - lobe median cells at higher magnification. Scale bars: $1 \& 4=250 \mu \mathrm{m} ; 2 \& 6=100 \mu \mathrm{m}$; $3 \& 7=50 \mu \mathrm{m} ; 5=200 \mu \mathrm{m} ; 8=20 \mu \mathrm{m}$. SEM micrographs made from the type. 

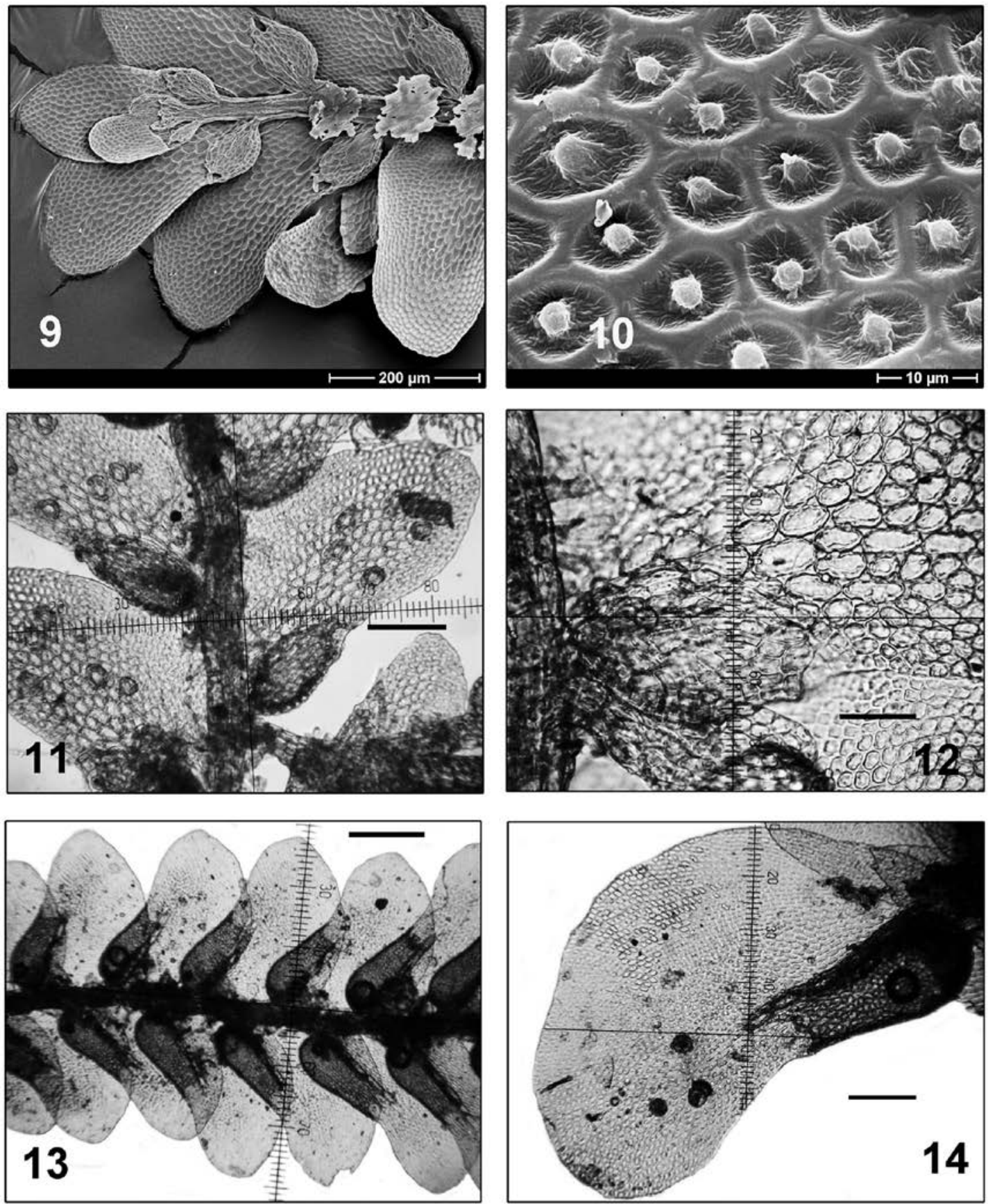

Figs 9-14. 9-12 - Cololejeunea floccosa var. fraseriana Pócs, var. nov. 9 - Habit, ventral view; 10 - lobe cells with papillae, dorsal view; 11 - habit, ventral view; 12 - basal lobe cells, ventral view. SEM and LM micrographs made from the type of var. 13 \& 14 - Cololejeunea cairnsiana Pócs, sp. nov. 13 - habit, ventral view; 14 - leaf, ventral view. LM micrographs made from the type. Scale bars: $9 \& 13=200 \mu \mathrm{m} ; 10=10 \mu \mathrm{m} ; 11 \& 14=100 \mu \mathrm{m} ; 12=50 \mu \mathrm{m}$. 
Arch. Ind:: 243, 1898, var. floccosa and the other known varieties by the lack of a true vitta. The vitta-like part of the lobe is not sharply delimited and not composed of real ocelli, only of chlorophyllose cells, which are larger but show a gradual transition into normal lobe cells. Similar pseudovitta can be observed in the pantropical Cololejeunea platyneura (Spruce) A. Evans.

ETYMology. The variety is named after its locality, the world's largest sandy island, rich in endemic taxa.

\section{Cololejeunea cairnsiana Pócs, sp. nov.}

Figs 13-20

\section{C. subg. Taeniolejeunea (Zwickel) Benedix}

TYPE MATERIAL: Northern QUEENSLAND: Paluma Range National Park, Paluma Dam road, $1.6 \mathrm{~km} \mathrm{~N}$ from the Paluma-Ewan Road, $19^{\circ} 00.02^{\prime} \mathrm{S}, 146^{\circ} 10.67^{\prime} \mathrm{E}$, $880 \mathrm{~m}$ alt., S. \& T. Pócs, A. Cairns, E.A. Brown \& Ch. Cargill 01122/Z [HOLOTYPE: BRI, ISOTYPE (microslide only) EGR]. Epiphyllous, in montane rainforest edge. It grows together with Allorgella australiensis (B.M. Thiers) Bechteler et al., Cololejeunea appressa (A. Evans) Benedix, Cololejeunea floccosa (Lehm. \& Linendb.) Steph., Cololejeunea floccosa var. amoenoides Tixier, Cololejeunea gottschei (Steph.) Mizut., Cololejeunea inflectens (Mitt.) Benedix and Lejeunea apiculata Sande Lac.

Medium-size epiphyllous plant adhering to leaf, forming pale, shiny green patches up to $2 \mathrm{~cm}$ in diameter. Shoots up to $1.2-1.4 \mathrm{~mm}$ wide, pinnately branching. Stem $40-64 \mu \mathrm{m}$ thick, with ventral merophyte of one row of cells, with a few rhizoids in each bundle, $8-10 \mu \mathrm{m}$ wide, short and colorless. Leaves oblong-ovate, falcate, with rounded apex, 450-640 × 240-320 $\mu \mathrm{m}$. Marginal lobe cells more or less quadrangular, 6-8 $\times 8-12 \mu \mathrm{m}$. Median lobe cells isodiametric or elongate hexagonal, $10-14 \times 14-20 \mu \mathrm{m}$, dorsal side tipped by round papilla of $4 \mu \mathrm{m}$ diameter. Basal cells more elongate, reaching $280 \mu \mathrm{m}$ length. Vitta sharply delimited, slightly exceeding length of lobule, formed by one row of 4-6 thickwalled ocelli, $50-65 \times 20-28 \mu \mathrm{m}$ each, with yellowish-brown content when dry. Main vitta often accompanied by second or even third halfrow formed by smaller cells near its end. Lobule near half of lobe length, ampulliform, elongate with truncate apex, $220-280 \times 100-120 \mu \mathrm{m}$ at its base, tapering at its $65-70 \mu \mathrm{m}$ wide end. Lobule bordered by 1-2 rows of elongate cells, other lobule cells subquadrate, $10-14 \times 4-8 \mu \mathrm{m}$, with thick walls, with intermediate thickenings here and there. Lobule teeth usually cross each other. First tooth falcate, lanceolate, turning upwards, formed by 2-4 uniseriate cells. Hyaline papilla globose, lateral at proximal side of first tooth. Second tooth triangular, at base $2-3$ cells wide, usually much longer than the first one, formed by 3-7 cells, often ending in acute, falcate, uniseriate apex which turns downward and can sometimes exceed the lobule margin. Dioicous, only female plants known. Gynoecium on short lateral branches. Female bracts $320-480 \mu \mathrm{m}$ long, ovate, reaching approximately to $3 / 4$ length of perianths; lobule cuneate, 300-360 $\mu \mathrm{m}$ long, with truncate and dentato-serrate apex. Perianth cuneate, truncate, 520-640 $\times 400 \mu \mathrm{m}$, ventrally bulging, with two compressed lateral wings, beak low, one cell high. Sporophytes and gemmae not seen, only gemmae scars on lobe.

ETYMology. The new species is named after Andi Cairns, biologist of James Cook University, Townsville, Queensland, who kindly showed me her investigation areas in Paluma Range and took part in the collection of the new species.

Other SPECIMEN SEen (PARATyPe): Northern Queensland, Broadwater, Abergowrie State Forest, $34 \mathrm{~km} \mathrm{NW}$ of Ingham, $28 \mathrm{~m}$ alt, $18^{\circ} 25.4^{\prime} \mathrm{S}$, $145^{\circ} 56.6^{\prime} \mathrm{E}$. Epiphyllous in waterlogged lowland rain forest with many palms and giant buttressed Ficus albipila and F. superba, Pócs \& Streimann, 99125/V (EGR). Accompanied by Cololejeunea appressa (A. Evans) Benedix, Cololejeunea floccosa var. amoenoides Tixier, Cololejeunea inflata Steph., Colura acroloba (Mont.) Steph., Drepanolejeunea sp., Leptolejeunea sp. and Microlejeunea bischlerae (B. M. Thiers) B. M. Thiers, Pócs \& Streimann 99125/Z (microslide in EGR). The last species is the first record since its original description (Thiers 1997; Thiers et al. 2012).

The species obviously belongs to Sect. Leonidentes Benedix, Feddes Repert. Spec. Nov. Regni Veg. Beih. 134: 38, 1953, and its closest relative 

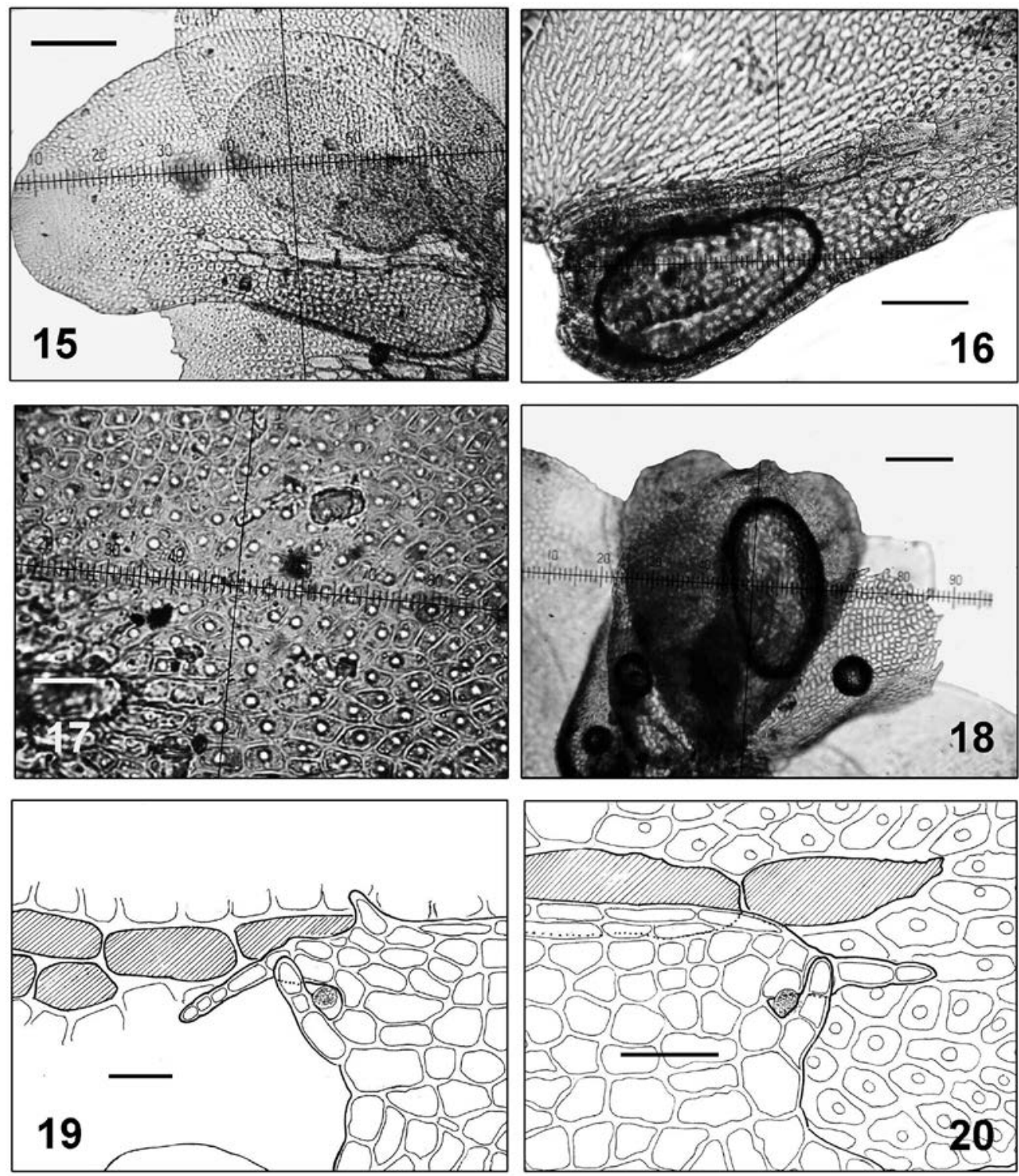

Figs 15-20. Cololejeunea cairnsiana Pócs, sp. nov. 15 - leaf, ventral view; 16 - lobule, ventral view; 17 - median lobe cells; 18 - perianth; $19 \& 20$ - lobule teeth and hyaline papilla. 15,16, 18 and 19 made from the type, 17 and 20 from the paratype No. $99125 /$ V. Scale bars: $15 \& 18=100 \mu \mathrm{m} ; 16=50 \mu \mathrm{m} ; 17 \& 19$ and $20=20 \mu \mathrm{m}$.

is Cololejeunea cambodiana Tixier, Rev. Bryol. et Lichénol. 36 (3/4): 578, '1969' (1970) nom. inval. (ICN Art. 37.1; based on more than one gathering). Tixier cited four specimens from Cambodia as types. The name should be validated, as follows:

\section{Cololejeunea cambodiana Tixier, sp. nov.}

TyPE: Cambodia, Kampot, Mt. Bokor, épiphylle en forêt taillis, 900 m, 17. XI. 1967, P. Tixier 2792 (HOLOTYPE: PC 0101211). The description in Tixier (1969: 577), together with the type specimen specified here, validates the name. 
Cololejeunea cairnsiana differs from C. cambodiana by its narrower, more falcate leaves with a flask-shaped lobule, its mostly uniseriate vitta, and its compressed perianth without ventral plicae.

\section{ENUMERATION OF THE AUSTRALIAN SPECIES}

This enumeration follows the classic division of subgenera, in alphabetic order similar to the account by Thiers (1988), even though their delimitation has not been supported by molecular research (Yu et al. 2013) due to the homoplasy of certain subgeneric characters. There have been some nomenclatural changes since the account of Thiers, as in the meantime the genus Aphanolejeunea has been merged into the genus Cololejeunea (Pócs \& Bernecker 2009) as a subgenus based on molecular research, and Cololejeunea minutissima (Sm.) Schiffn. has been transferred into the genus Myriocoleopsis (Yu et al. 2014). Some species names used in the catalogues of McCarthy $(2003$, 2006) have since been synonymized, in accordance with the new world checklist (Söderström et al. 2016) and Söderström et al. (2015) on the validation of Lejeuneaceae genera. These names are therefore listed as synonyms under the relevant species, for convenience. There are 2 species with an uncertain taxonomic position. Any synonymization of these species should be done only after thorough comparison of their types and perhaps molecular studies. Occurrence in the different states of Australia is given by the abbreviations NSW for New South Wales, QLD for Queensland, VIC for Victoria and TAS for Tasmania. Detailed distributional data in Australia are given only in cases where the records are new for Australia or for a state, or where there is only a single previous record for the relevant state. The year of collection is easy to read from the first two digits of the collection numbers $(99,00$ and 01 for 1999, 2000 or 2001). These are followed by the general worldwide distribution. Because Cololejeunea species are in most localities epiphyllous, the substrate is mentioned in the habitat description only when it is not a living leaf. A selected list of the best illustrations of each species is also given. The collected specimens are deposited in EGR, CANB, NSW and BRI.

I. Cololejeunea subg. Aphanolejeunea (A. Evans) Benedix

Beih. Feddes Repert. 134: 15, 1953.

1. Cololejeunea papillosa (K. I. Goebel) Mizut.

J. Hattori Bot. Lab. 29: 156. 1966.

Aphanolejeunea borneensis (Herz.) Pócs, J. Hattori Bot. Lab. 55: 309. 1954.

Literature ReCORDS: Pócs \& Streimann (1999: 168), McCarthy (2003: 11).

Distribution. QLD. Tricontinental, also in America and Asia (Pócs \& Bernecker 2009).

Illustrations: Herzog (1950: 324, fig. 3 as Aphanolejeunea microscopica var. borneensis Herzog), Pócs [1994: 461, figs 13-18, as Aphanolejeunea borneensis (Herzog) Pócs].

2. Cololejeunea sintenisii (Steph.) Pócs in Pócs $\&$ Bernecker

Polish Bot. J. 54: 8. 2009.

Aphanolejeunea angustiloba Horik., J. Sci. Hiroshima Univ., ser. B, 2(1): 91.1932.

Literature ReCORDS: Pócs \& Streimann (1999: 168), McCarthy (2003: 10).

Distribution. QLD. Pantropical (Pócs \& Bernecker 2009).

ILLUSTRATIONS: Allorge \& Jovet-Ast (1950 as Aphanolejeunea teotonii V. Allorge \& Jovet-Ast), Schuster (1980: 1304, fig. 771 as Aphanolejeunea ephemeroides R. M. Schust.), Zhu \& So (2001: 370, fig. 138 as Aphanolejeunea angustiloba Horik.).

3. Cololejeunea thiersiae (Pócs) Pócs in Pócs \& Bernecker

Polish Bot. J. 54: 9. 2009.

Aphanolejeunea thiersiae Pócs, Hikobia 11: 459. 1994.

LITERATURE RECORDS: McCarthy (2003: 11).

DisTRIBUTION. QLD. Endemic.

Illustration: Pócs (1994: 460, figs 7-12, as Aphanolejeunea thiersiae Pócs). 


\section{Cololejeunea veillonii Tixier}

Nova Hedwigia 31: 757. 1979.

Aphanolejeunea veillonii (Tixier) Pócs, J. Hattori Bot. Lab. 55: 311. 1984.

Literature ReCORDS: Pócs \& Streimann (1999: 168), McCarthy (2003: 11).

Distribution. QLD. Tropical Asian - Pacific: Philippines, Malaysia, Australia, New Guinea, New Caledonia, Fiji (Hürlimann 1987; Pócs \& Piippo 1999, 2011; Pócs \& Bernecker 2009).

Illustrations: Tixier (1979: 758, fig. 19), Pócs \& Piippo [1999: 99, fig. 10, as Aphanolejeunea veillonii (Tixier) Pócs].

\section{Cololejeunea subg. Cololejeunea}

5. Cololejeunea haskarliana (Lehm. \& Lindenb. in Lehmann) Schiffn.

Consp. Hepat. Arch. Ind.: 244. 1898.

LiteratuRe ReCORdS: Pócs \& Streimann (2006: 21); Renner (2011: 564).

Distribution. QLD. Widespread from the East African Islands (Seychelles and Réunion) throughout Indomalesia to Japan and to Fiji (Pócs \& Streimann 2006).

Illustrations: Benedix (1953: tabs 18, 19a-b, 40a-b), Tixier (1985: 224, fig. 19), Zhu \& So (2001: 317, fig. 119).

6. Cololejeunea mamillata (Ångstr.) E. A. Hodgs. Trans. Roy. Soc. New Zealand, Bot. 3(11): 184. 1967.

LITERATURE RECORDS: Windolf (1987: 395), Thiers (1990: 277), Bolin \& Henderson (2002: 224); McCarthy (2003: 32).

DisTribution. QLD, NSW. Southern temperate: Chile, Australia, New Zealand (Pócs 1984).

ILluSTRATION: Thiers (1988: 117, plate 1, figs 1-4).

\section{Cololejeunea schmidtii Steph.}

Bot. Tidskr. 24(3): 278. 1902.

LiteratuRe ReCORDS: Pócs \& Streimann (2006: 21).

Distribution. QLD. Southeast Asiatic, Distributed from Sri Lanka to Japan and to Fiji (Pócs et al. 2011).
ILLUSTRATIONS: Tixier (1977: 255-263, figs. 1-8), Zhu \& So (2001: 334, fig. 125).

\section{Cololejeunea tenella Benedix}

Feddes Repert. Spec. Nov. Regni Veg. Beih. 134: 55. 1953.

LiterATURE RECORDS: Thiers (1988: 125), Scott (1997: 105), Bolin \& Henderson (2002: 224), McCarthy (2003: 11).

Notes. New for New South Wales: Dorrigo National Park, along Rosewood Creek track, 600-730 m, in subtropical rainforest with many vines and epiphytes, S. \& T. Pócs \& E.A. Brown 009/BK. Whian Whian State Forest, 'Rocky Creek' near causeway of Rummery Road, $250 \mathrm{~m}$, riverine forest on rocky streamside, $S$. \& T. Pócs \& E.A. Brown 0028/M. Border Ranges National Park, Bar Mountain, at the picnic area on $\mathrm{W}$ edge of caldera rim. $900 \mathrm{~m}$, temperate rain forest with $\mathrm{No}$ thofagus cunninghamii. S. \& T. Pócs \& E.A. Brown 0036/AC. Border Ranges National Park, Brindle Creek, along Helmholtzia Loop, $750 \mathrm{~m}$, in wet subtropical rainforest. S. \& T. Pócs \& E.A. Brown 0039/N. Wilson River Flora Reserve in Mt. Boss State Forest, $35 \mathrm{~km}$ WSW of Kempsey, $610 \mathrm{~m}$, in rich subtropical rain forest full of epiphytes, S. \& T. Pócs \& E.A. Brown 0047/AA.

DisTRIBUTION. QLD, NSW. Widespread in Indomalesia.

ILLUSTRATIONS: Benedix (1953: tab. 17a-c), Tixier (1985: 210-211, figs. 11-12), Thiers (1988: 117, figs. 5-9).

III. Cololejeunea subg. Cryptolejeunea Benedix

Feddes Repert. Spec. Nov. Regni Veg. Beih. 134: 77. 1953.

9. Cololejeunea inflectens (Mitt.) Benedix

Feddes Repert. Spec. Nov. Regni Veg. Beih. 134: 79. 1953. Cololejeunea peculiaris (Herzog) Benedix, Feddes Rep. Beih. 134: 42, 1953.

Literature ReCORDS: Thiers (1988: 120), Bolin \& Henderson (2002: 224), McCarthy (2003: 32).

Distribution. QLD. Palaeotropical species, distributed from the Comoros, Madagascar and the Seychelles to Fiji (Pócs et al. 2011).

ILLuSTRATIONS: Benedix [1953: 134, tab. 30, figs 
d-f as Cololejeunea peculiaris (Herz.) Benedix], Tixier (1979: 776: fig. 2; Thiers 1988: 119, Plate 2).

IV. Cololejeunea subg. Diaphanae R. M. Schust.

J. Elisha Mitchell Sci. Soc. 72(1): 103. 1956.

Incalejeunea Tixier ex Pócs, Acta Bryolich. Asiatica 4: 129. 2011.

10. Cololejeunea amphibola B. M. Thiers

Beih. Nova Hedwigia 90: 130. 1988.

Aphanolejeunea amphibola (B. M. Thiers) Pócs \& Bernecker in Pócs \& Piippo, Acta Bot. Fenn. 165: 87. 1999.

LiterATURE RECORDS: Windolf (1987: 395), Scott (1997: 105), Pócs \& Piippo (1999: 87), Pócs \& Streimann (1999: 168), Bolin \& Henderson (2002: 224).

Note. New for New South Wales: Border Ranges National Park, Brindle Creek along Helmholtzia Loop, $750 \mathrm{~m}, S . \&$ T. Pócs \& E.A. Brown 0039/X.

Distribution. QLD, NSW. Also Borneo, Malaysia, Sulawesi, New Guinea, Fiji (Pócs et al. 2011; Pócs \& Lee 2016).

Illustrations: Thiers (1988: 131, pl. 7), Pócs \& Piippo [1999: 88, as Aphanolejeunea amphibola (B. M. Thiers) Pócs \& Bernecker].

\section{Cololejeunea diaphana A. Evans var. cristulata R. M. Schust.}

J. Elisha Mitchell Sci. Soc. 72(1): 112. 1956.

Note. New for Australia: Queensland, Atherton Tableland. Hugh Nelson Range. Summit around telecommunication tower, $22 \mathrm{~km} \mathrm{~S}$ of Atherton, $1240 \mathrm{~m}$, in somewhat disturbed montane rainforest dominated by Acacia and Alphitonia, Pócs \& Streimann 99109/BU.

Distribution. QLD. Pantropical species. Both var. diaphana with smooth cells and var. cristulata with conical papillae and dentate leaf margin are widespread worldwide.

ILLUSTRATION: Schuster (1980: 1299: fig. 769).

12. Cololejeunea iwatsukiana (Pócs) Pócs in Pócs \& Bernecker

Polish Bot. J. 54: 6. 2009.

Aphanolejeunea iwatsukiana Pócs, Hikobia 11: 457. 1994.
Literature ReCORDS: Pócs (1994: 457), McCarthy (2003: 11).

DisTRIBUTION. QLD. Endemic.

Illustration: Pócs (1994: 458, figs 1-6, as Aphanolejeunea iwatsukiana Pócs).

Note. This stands near the previous species, and its taxonomic position needs to be clarified.

\section{Cololejeunea wightii Steph.}

Hedwigia 34(5): 253. 1895.

LitERATURE RECORDS: Windolf (1985a: 174), Scott (1987: 64; 1997: 105), Thiers (1988: 135), Piippo (1994: 54), Bolin \& Henderson (2002: 224), McCarthy (2003: 33).

Distribution. QLD. Widely distributed Pantropical species.

Illustrations: Miller et al. (1963, pl. 21), Tixier (1985: 249, fig. 31), Thiers (1988: 136, pl. 9), Zhu \& So (1999: 169, fig. 3).

V. Cololejeunea subg. Leptocolea (Spruce) Schiffn. Hepat. (Engl.-Prantl): 122. 1893.

\section{Cololejeunea cordiflora Steph.}

Hedwigia 34(5): 246. 1895.

Cololejeunea trichomanis subsp. cordiflora (Steph.) Pócs, in Pócs \& Piippo, Acta Bryolichenol. Asiatica 4:104. 2011.

Notes. Plants resembling Cololejeunea cordiflora with a unicellular stylus were considered as a synonym or subspecies of Cololejeunea trichomanis (Gottsche) Besch. Rev. Bryol. 19: 14.1892 = Cololejeunea goebelii (Gottsche ex Schiffn.) Schiffn., Bot. Jahrb. Syst. 3: 581. 1897 (Thiers 1988, Pócs in Pócs \& Piippo 2011). Both Cololejeunea trichomanis (with a threadlike stylus) and C. cordiflora [with a 1(-2)-celled stylus] apparently occur near the type locality of C. trichomanis in Australia, but molecular investigations have shown that they are distinct species (Yu et al. 2013).

LITERATURE RECORDS: Pócs \& Streimann (1999: 169), McCarthy (2003: 31 as 'Cololejeunea cordifolia' Steph.).

New ReCORDS: Queensland, Atherton Tableland, Mt. 
Baldy 4 km WSW of Atherton, 1060 m, in AraucariaAcacia plantation, Pócs \& Streimann 99108/AQ; Main Coast Range, Mt. Lewis summit, 951-1240 m, in montane forest, Pócs \& Streimann 99111/AO, S. \& T. Pócs, A. Cairns \& E.A. Brown \& Ch. Cargill 01085/V; along Butchers Creek $27 \mathrm{~km}$ SE of Atherton, $780 \mathrm{~m}$, in submontane rainforest remnants, Pócs \& Streimann 99116/B; Paluma Range, Crystal Creek National Park (now in Paluma Range National Park), on ridge leading to Witts Lookout, $930-950 \mathrm{~m}$, in montane rainforest, S. \& T. Pócs 01123/F.

Distribution. QLD. Widespread Indomalesian-Pacific species (Pócs \& Piippo 2011).

Illustrations: Tixier (1979: 766, fig. 24), Tixier (1985: 279), Pócs \& Piippo (2011: c-h, k).

15. Cololejeunea gottschei (Steph.) Pande, K. P. Srivast. \& Ahmad Figs $21 \& 22$

J. Indian Bot. Soc. 36(3): 345. 1957.

Notes. New for Australia: Queensland, Paluma Range National Park, Benhams track near Hermit Creek crossing, above Benhams Falls, $890 \mathrm{~m}$, in open, wet Eucalyptus and Leptospermum forest, S. \& T. Pócs, A.Cairns \& E.A. Brown \& Ch. Cargill 01116/AM; same State Forest, Birthday Creek, 840-870 m, in vine forest, S. \& T. Pócs, A. Cairns \& E.A. Brown \& Ch. Cargill 01121/BJ; Paluma Dam forestry road, $880 \mathrm{~m}$, at forest edge, $S$. \& $T$. Pócs, A. Cairns \& E.A. Brown \& Ch. Cargill 01122/AD.

Distribution. QLD. Indomalesian species known from India to New Guinea (Pócs \& Ninh 2005).

ILluStRations: Mizutani (1965: 116, figs 8-14), Zhu \& So (2001: 306, fig. 116), Ashthana \& Srivastava (2003: 118, pl. 34).

16. Cololejeunea heinari Pócs, sp. nov. (see above)

All known specimens are from Queensland: Fraser Island, Great Sandy National Park.

Distribution. QLD.

17. Cololejeunea longifolia (Mitt.) Benedix ex Mizut.

Figs $23 \& 24$

J. Hattori Bot. Lab. 26: 184. 1963.

Notes. New for Australia: Queensland, Dain- tree National Park, Cape Tribulation, 'Botanical Circuit' along Noah Creek, $5 \mathrm{~m}$, in temporarily waterlogged lowland rainforest rich in Licuala palms and prop-rooted and cauliflorous trees, Pócs \& Streimann 9989/Z.

Distribution. QLD. Indomalesian-Pacific species known from India to Fiji (Zhu \& So 2001; Pócs et al. 2011).

ILLUSTRATIONS: Tixier (1984: 121-123, figs 11-13), Tixier (1985: 239, fig. 25), Zhu \& So (2001: 3069, fig. 117), Asthana \& Srivastava (2003: 119, pl. 35).

18. Cololejeunea obliqua (Nees \& Mont.) Schiffn. Bot. Jahrb. Syst. 23(5): 586. 1897.

LITERATURE RECORDS: Pócs \& Streimann (1999: 169).

New ReCORD: Queensland, Main Coast Range, Mt. Lewis, $1050 \mathrm{~m}$, on small trees in grazed opening, Pócs \& Streimann 99113/M.

Distribution. QLD. Widespread pantropical species (Zhu \& So 2001).

Illustrations: Benedix [1953: t. 25 as Cololejeunea nymanii (Steph.) Benedix; t. 26 as Cololejeunea jelinekii (Steph.) Benedix], Tixier [1985: 293, fig. 57 as Cololejeunea scabriflora (Gottsche) Schiffn.], Pócs \& Piippo (2011: 105, fig. 16: 1-n).

19. Cololejeunea trichomanis (Gottsche) Besch.

Rev. Bryol. 19(1): 14. 1892.

Cololejeunea goebelii (Gottsche ex Schiffn.) Schiffn., Consp. Hepat. Arch. Ind.: 244. 1898.

LiteratURE RECORDS: Tixier (1985: 193), Thiers (1988: 122), Piippo (1994: 54), Bolin \& Henderson (2002: 224), McCarthy (2003: 31), Pócs \& Piippo (2011: 104).

Note. All but one of the specimens investigated by Thiers (1988) belong to this species; the specimen from Russell River collected by Sayer, 1886 , NY, with a stylus only 1-2 cells long, seems to belong to $C$. cordiflora.

Distribution. QLD. Indomalesian species distributed from India to New Guinea (Pócs \& Piippo 2011).

Illustrations: Mizutani (1961: 253, fig. 31: 1-8), Asthana \& Srivastava [2003: 118, pl. 34: 8 as Cololejeunea trichomanis (Gottsche) Steph.], Pócs \& Piippo (2011: 105, fig. 16: a-b as Cololejeunea trichomanis). 

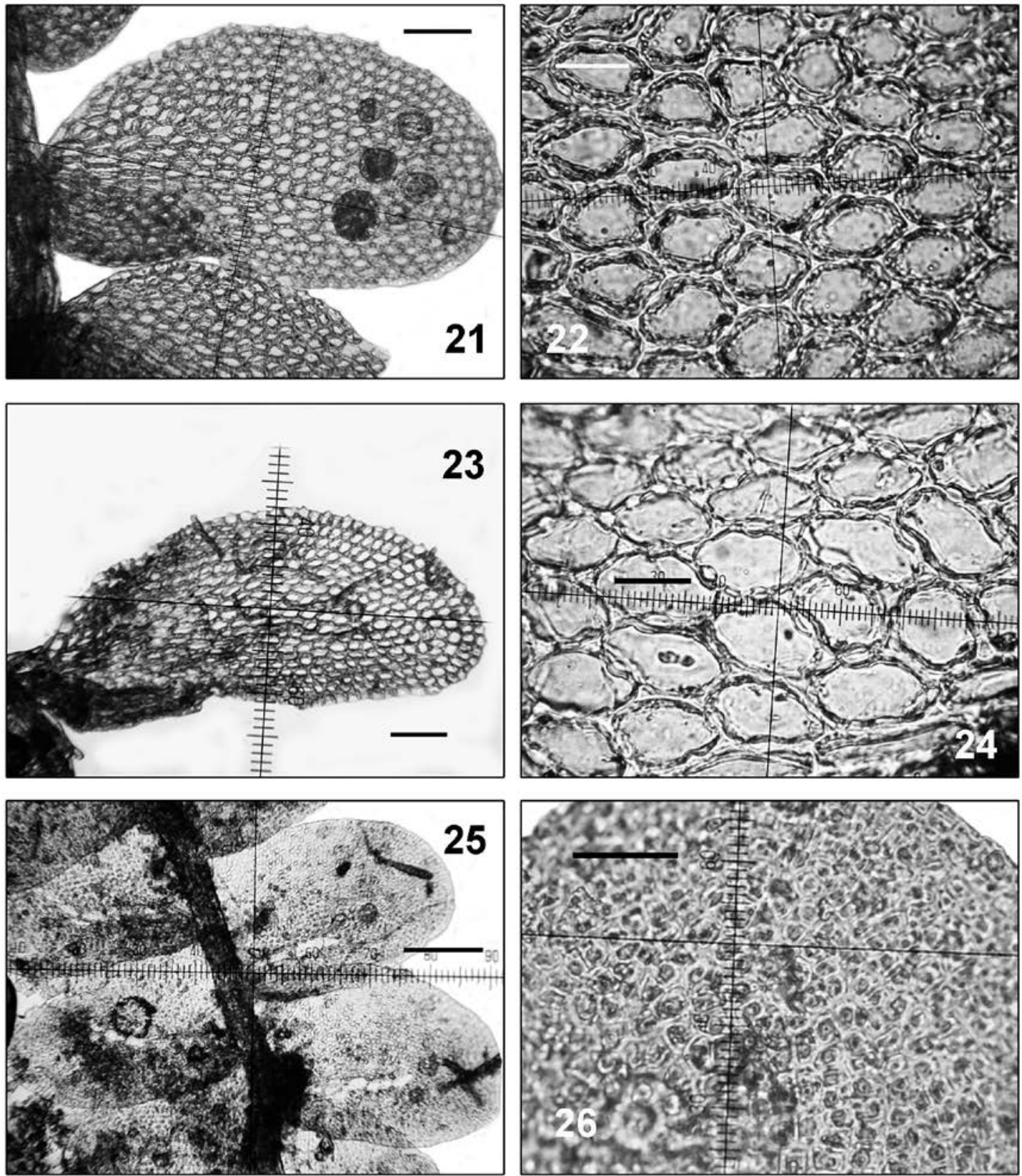

Figs 21-26. 21 \& 22 - Cololejeunea gottschei (Steph.) Pande et al., from No. 01116/AM. 21 - habit, ventral view; 22 - median lobe cells. 23 \& 24 - Cololejeunea longifolia (Mitt.) Benedix ex Mizut., from No. 9989/Z. 23 - leaf, ventral view; 24 - median lobe cells. 25 \& 26 - Cololejeunea verrucosa Steph., from No. 99104/J. 25 - habit, ventral view; 26 - median lobe cells with star-shaped papillae. Scale bars: $21,23,25=100 \mu \mathrm{m} ; 22,24,26=50 \mu \mathrm{m}$. 
VI. Cololejeunea subg. Pedinolejeunea Benedix ex Mizut.

J. Hattori Bot. Lab. 24: 240. 1961.

20. Cololejeunea cardiocarpa (Mont.) A. Evans

Mem. Torrey Bot. Club 8(2): 172. 1902.

Literature ReCORDS: Thiers (1988: 128), Bolin \& Henderson (2002: 224), McCarthy (2003: 31).

Note. New for New South Wales: Whian Whian State Forest, 'Rocky Creek' near causeway of Rummery Road, $250 \mathrm{~m}$, riverine forest on rocky streamside, $S$. \& T. Pócs \& E.A. Brown $0028 / N$.

Distribution. QLD, NSW. Cololejeunea cardiocarpa is very widespread in the Neotropics and in Africa and occurs in Eastern Australia and New Caledonia as well, never overlapping in its distribution with the vicariant Pacific and Indochinese C. pacifica Pócs (Pócs 2012; Chantanaorrapint \& Pócs 2014).

ILLUSTRATIONS: Jones (1957: 201, fig. 4), Schuster (1980: 1279, fig. 765), Tixier (1985: 47, fig. 19), Thiers (1988: 129, pl. 6: 5-8).

\section{Cololejeunea kapingaensis H. A. Mill.}

Bryologist 59(3): 170. 1956.

LiterATURE RECORDS: Pócs \& Streimann (2006: 21).

Distribution. QLD. Also Caroline Islands, Marshall and Fiji Islands, Bismarck Archipelago and Australia (Pócs \& Piippo 2011; Pócs et al. 2011).

IlluSTRations: Miller (1956: 171, figs a-1), Miller et al. (1963: pl. 21), Tixier (1985: 60, fig. 26).

22. Cololejeunea laevigata (Mitt.) R. M. Schust.

J. Hattori Bot. Lab. 26: 241. 1963.

LITERATURE RECORDS: From many localities enumerated in McCarthy (2003: 32).

Distribution. VIC, TAS. Temperate Australasian species known also from Lord Howe Island and New Zealand.

ILLUSTRATION: Thiers (1988: 129, pl. 6: 1-4).

\section{Cololejeunea lanciloba Steph.}

Hedwigia 34(5): 250. 1895.

LITERATURE RECORDS: From many localities enumerated in McCarthy (2003: 32).

Distribution. QLD, NSW. Pantropical species, common in Africa, Asia and in the Pacific, but rare in the Neotropics (Zhu \& So 2001; Pócs et al. 2014).

ILlustrations: Mizutani (1961: 246, fig. XXIX: 13-27), Vanden Berghen (1972: 475-476, figs. 19-20), Tixier (1985: 139, fig. 70 as Lejeunea bolombensis), Thiers (1988: 124, pl. 4), Zhu \& So (2001: 278, fig. 106), Asthana \& Srivastava (2003: pl. 28).

\section{Cololejeunea maritima Tixier}

Nova Hedwigia 31: 752. 1979.

LITERATURE RECORDS: Windolf (1985a: 174; 1985b: 76; 1987: 395), Bolin \& Henderson (2002: 224), McCarthy (2003: 32, where Thiers 1988: 116 is cited erroneously).

Note. The species is very closely related to and probably synonymous with Cololejeunea lanciloba, as Zhu and So (2001) already mentioned.

DisTRIBUTION. QLD. Known also from Indonesia (Java), Bangladesh, Thailand, Malaysia and New Caledonia (Tixier 1985), Tonga (Hürlimann 1987).

ILluSTRATIONS: Tixier (1979: 753, fig. 17), Tixier (1985: 162, fig. 82).

25. Cololejeunea planissima (Mitt.) Abeyw.

Ceylon J. Sci., Biol. Sci. 2(1): 73. 1959.

Cololejeunea aoshimensis Horik., J. Sci. Hiroshima Univ., Ser. B, Div. 2, Bot. 1: 20. 1931.

LITERATURE RECORDS: Bolin \& Henderson (2002: 224), McCarthy (2003: 31).

NotE. Although Meagher (2003) doubted its occurrence in Australia, the following new record seems to confirm it: Queensland, Fraser Island, Great Sandy National Park, E of Central Station, $65 \mathrm{~m}$, in Araucaria cunninghamii plantation, Pócs \& Streimann 9962/D.

Distribution. QLD. Widespread in the Paleotropics but very rare in the Neotropics (Pócs et al. 2014). 
ILlustrations: Mizutani (1961: 246, fig. XXIX: 1-27), Hattori \& Noguchi (1954: 64, figs 15-21), Mizutani (1984: 433, fig. 3), Zhu \& So (2001: 281, fig. 107), Asthana \& Srivastava (2003: 109-110, pl. 25-26).

\section{Cololejeunea raduliloba Steph.}

Hedwigia 34(5): 251. 1895.

Literature ReCORDS: Thiers (1988: 125), Bolin \& Henderson (2002: 224), McCarthy (2003: 33).

Distribution. QLD. Widespread in Asia and in the Pacific, in Africa only on the Indian Ocean islands.

ILluSTRATIONS: Horikawa (1931: 7, fig. 10: 1-8), Mizutani (1961: 244, fig. 28: 1-10), Tixier 1985: 105, fig. 52), Thiers (1988: 126, pl. 5), Zhu (1995: 98, fig. 10).

\section{Cololejeunea stylosa Steph. in A. Evans}

Trans. Connecticut Acad. Arts 10(8): 454. 1900.

Cololejeunea bokorensis Tixier, Bryophyt. Biblioth. 18: 64. 1979.

Literature ReCORDS: Pócs \& Streimann (1999: 169), McCarthy (2003: 169, sub Cololejeunea bokorensis).

Distribution. QLD. Widespread in Asia, from China and Malaysia to the Pacific: Fiji and Micronesia (Zhu \& So 2001; Pócs et al. 2011).

Illustrations: Mizutani (1984: 435, fig. 4), Tixier (1985: 34, fig. 11; 40, fig. 15, sub Cololejeunea bokorensis Tixier), Zhu \& So (2001: 271, fig. 104).

\section{Cololejeunea triapiculata (Herzog) Tixier}

Gard. Bull. Singapore 25(3): 344. 1971.

LITERATURE RECORDS: Renner (2011: 566).

Note. New for New South Wales: Dorrigo National Park, along Rosewood Creek track, 600-730 m, in subtropical rainforest with many vines and epiphytes, $S$. \& T. Pócs \& E.A. Brown 009/BP.

Distribution. NSW, QLD: Renner (2011) reported it from Cook, Wooroonooran National Park.

Indomalesian species distributed from Sri Lanka through Sumatra and Java to Malaysia and New Guinea (Tixier 1985; Pócs \& Piippo 2011).
ILluSTRATIONS: Herzog (1932: 95, fig. 8: 6 sub Leptocolea triapiculata Herz.), Tixier (1985: 87, fig. 41), Renner (2011: 569, fig. 2).

\section{Cololejeunea vidaliana Tixier}

Nat. Hist. Bull. Siam Soc. 24: 444. 1973.

Cololejeunea bokorensis Tixier, Bryophyt. Biblioth. 18: 64. 1979.

LiterATURE RECORDS: O'Shea et al. (1997: 180), McCarthy (2003: 33), Pócs \& Streimann (2006: 21).

Distribution. QLD. Widespread in tropical Africa, Asia to Australia and New Caledonia and Tonga (Mizutani 1984; Tixier 1985; Hürlimann 1987; Wigginton 2009). The species is closely related to Cololejeunea stylosa (Steph.) A. Evans., a species widespread in tropical Asia.

ILlustrations: Jones (1957: 201: fig. 4 a-b, 204, fig. $5 \mathrm{f}-\mathrm{g}$ sub Leptocolea punctata $\mathrm{E}$. W. Jones), Tixier (1979: 180, fig. 4), Mizutani (1984: 436, fig. 5), Tixier (1985: 32, fig. 10), Tixier (1985: 40, fig. 15 sub Cololejeunea bokorensis Tixier).

VII. Cololejeunea subg. Taeniolejeunea (Zwickel) Benedix

Feddes Repert. Spec. Nov. Regni Veg. Beih. 134: 21. 1953.

30. Cololejeunea appressa (A. Evans) Benedix

Feddes Repert. Spec. Nov. Regni Veg. Beih. 134: 31. 1953.

LiterATURE RECORDS: Thiers (1988: 139; 1990; 277), Piippo (1994: 54), Pócs \& Streimann (1999: 169), Bolin \& Henderson (2002: 224), McCarthy (2003: 31).

Notes. New for New South Wales: Nightcap National Park, Palm Valley below Minyon Falls, 110-150 m, subtropical rain forest rich in palms, on Acanthophoenix cunninghamii leaves, S. \& T. Pócs \& E.A. Brown 0026/AK. Nightcap National Park, Turntable Creek below Turntable Falls, 250-300 m, on liana stem, S. \& T. Pócs \& E.A. Brown 0030/T and AE. Mt. Warning National Park, Corrumbin Creek below the picnic area. $28^{\circ} 23.6^{\prime} \mathrm{S}, 153^{\circ} 35^{\prime} \mathrm{E}$, in degraded subtropical rain forest, $S$. \& T. Pócs \& E.A. Brown 0032/O.

Distribution. NSW, QLD. Widespread Pantropical species. 
ILlustrations: Benedix (1953: t. 8 g-h), Jones (1968: 570, fig. 4a), Tixier (1979: 736, fig. 8), Thiers (1988: 138, pl. 10), Zhu (1995: 84, fig. 1), Zhu \& So (2001: 15, fig. 5c), Asthana \& Srivastava (2003: 126127, pl. 42-43).

31. Cololejeunea cairnsiana Pócs, sp. nov. (see above)

All known specimens are from Queensland: Paluma Range National Park, and Broadwater in Abergowrie State Forest. Seems to be endemic to Queensland.

\section{DisTRIBUTION. QLD.}

\section{Cololejeunea falcata (Horik.) Benedix}

Feddes Repert. Spec. Nov. Regni Veg. Beih. 134: 29. 1953.

Literature ReCORds: Thiers (1988: 139), Pócs \& Streimann (1999: 169), Bolin \& Henderson (2002: 224), McCarthy (2003: 31).

Distribution. QLD. Palaeotropical species, but rare in America: Brazil (Pócs in Gradstein \& Costa 2003); Africa: only Madagascar (Wigginton 2009). Widespread in tropical Asia and Australia, and rare in the Pacific: New Caledonia, Guam, Ryukyu (Miller et al. 1963; Pócs \& Piippo 2011), Tonga (Hürlimann 1987).

Illustrations: Horikawa (1931: 22, fig. 6: 1-9), Benedix (1953: tab. 7 as Cololejeunea falcatoides Benedix), Tixier (1979: 738, fig. 9), Thiers (1988: 140: pl. 11), Zhu (1995: 85, fig. 2).

33a. Cololejeunea floccosa (Lehm. \& Lindenb. in Lehm.) Schiffn. var. floccosa

Consp. Hepat. Arch. Ind.: 243. 1898.

LITERATURE RECORDS: Windolf (1987: 395), Thiers (1988: 141), Piippo (1994: 54), Pócs \& Streimann (1999: 169), Bolin \& Henderson (2002: 224), McCarthy (2003: 31).

Note. New for New South Wales: Dorrigo National Park, along Rosewood Creek track, 600-730 m, accompanied by Siphonolejeunea elegantissima, in subtropical lowland rainforest with many epiphytes, $S$. \& T. Pócs \& E.A. Brown $009 / B N$.

Distribution. NSW, QLD. Widespread in tropical Africa, Asia, Australia and New Caledonia, rare in New Guinea.

Illustrations: Benedix (1953: tab. 4, figs. a-b), Mizutani (1984: 167, fig. 6), Jones (1968: 570, fig. 4c), Tixier (1979: 730, fig. 4), Thiers (1988: 142, pl. 12), Zhu \& So (2001: 343).

\section{3b. Cololejeunea floccosa var. amoenoides}

Tixier

Figs 29-32

Cryptog. Bryol. Lichénol. 2(1): 59. 1981.

Notes. The variety is new for Australia: New South Wales: Nightcap National Park, in Palm Valley, below Minyon Falls, 110-150 m, in subtropical rain forest rich in palms (Acanthophoenix cunninghamii), S. \& T. Pócs \& E.A. Brown 0026/AB; Border Ranges National Park, Pinnacle Lookout at inner side of $\mathrm{W}$ caldera rim at $800 \mathrm{~m}$ alt., at border between cool temperate rain forest with Nothofagus cunninghamii and open Acacia - Xanthorrhoea bush with 2-3 m tall Xanthorrhoea trees, S. \& T. Pócs \& E.A. Brown 0038/N; same National Park, Brindle Creek, along Helmholtzia Loop, in subtropical rain forest, $S . \& T$. Pócs \& E.A. Brown 0039/Z; Wilson River Flora Reserve in Mt. Boss State Forest, $35 \mathrm{~km}$ WSW of Kempsey, $610 \mathrm{~m}$, in rich subtropical rainforest full of epiphytes, S. \& T. Pócs \& E.A. Brown 0047/Y. - Queensland: 'The Boulders' rainforest reserve along Babinda Creek, $5 \mathrm{~km} \mathrm{~W}$ of Babinda town, $85 \mathrm{~m}$, in lowland rainforest rich in epiphytes, interwoven by rattan (Calamus) palm, Pócs \& Streimann 9983/AY; Main Coast Range, Daintree River National Park, Mossmann Gorge area 4-5 km W of Mossman town, 110-160 m, in tropical lowland rainforest with many buttressed trees, Pócs \& Streimann 9986/T; Daintree National Park, Cape Tribulation, 'Botanical Circuit' along Noah Creek, $5 \mathrm{~m}, 16^{\circ} 8.8^{\prime} \mathrm{S}, 145^{\circ} 26.6^{\prime} \mathrm{E}$, in temporarily waterlogged lowland rainforest, rich in Licuala palms and prop-rooted and cauliflorous trees, Pócs \& Streimann 9989/AA; E edge of Atherton Tableland, Wooronooran National Park, Henrietta Creek, $33 \mathrm{~km}$ WSW of Innisfail, along Palmerston Highway, $375 \mathrm{~m}$, in lowland rainforest with scattered Agathis robusta trees. Pócs \& Streimann 99117/AB; Kirrama Range, Flat Creek along 

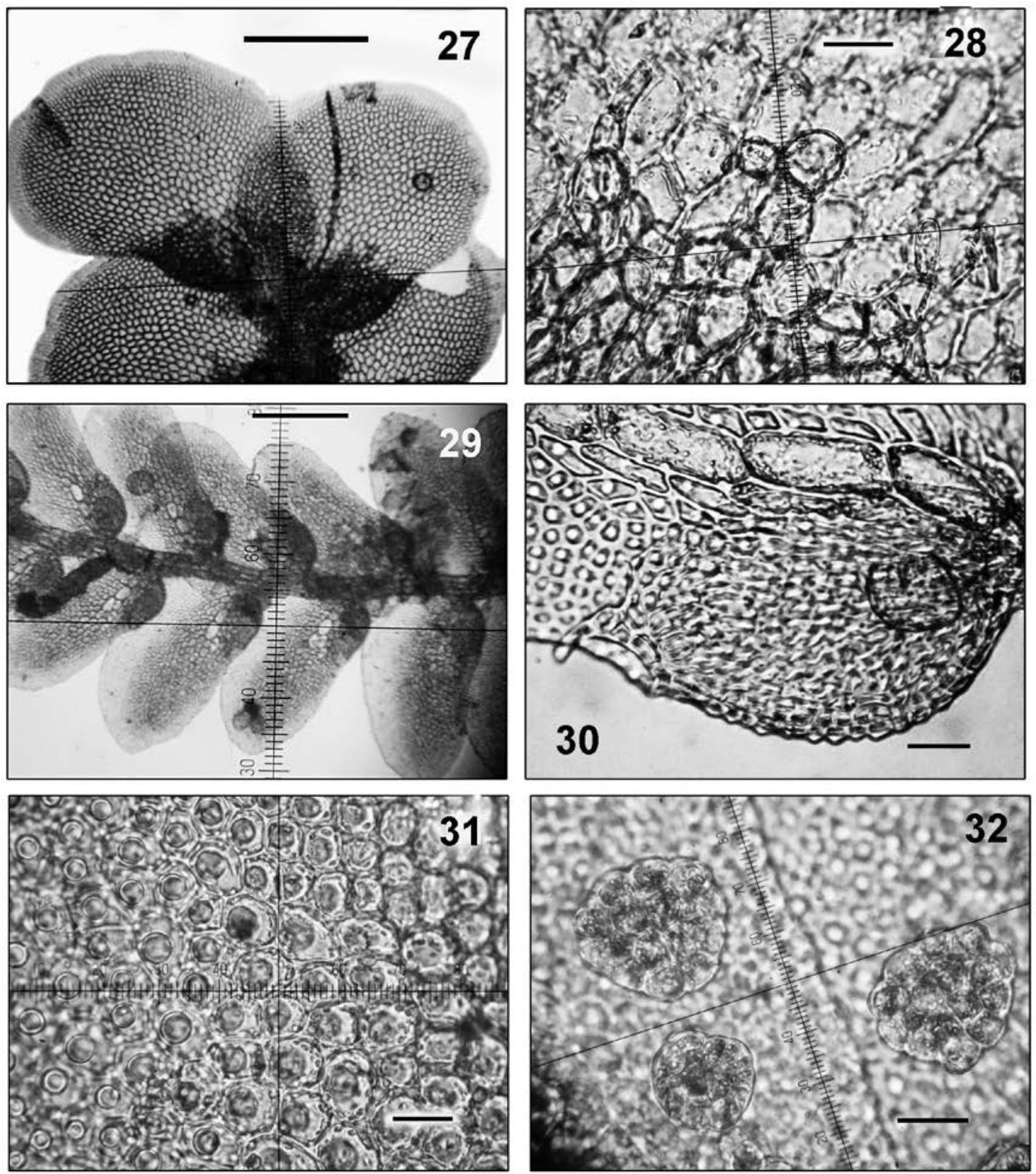

Figs 27-32. 27 \& 28 - Cololejeunea triapiculata (Herzog) Tixier, from 009/BP. 27 - habit, ventral view; 28 - lobule teeth with hyaline papilla. 29-30. Cololejeunea floccosa var. amoenoides Tixier, from 0047/Y (29 \& 30) and from 026/AB (31 \& 32). 29 - habit, ventral view; 30 - lobule and vitta; 31 - median lobe cells with large, round papillae; 32 - discoid gemmae. Scale bars: $27 \& 29=200 \mu \mathrm{m} ; 28,30,31=20 \mu \mathrm{m}, 32=25 \mu \mathrm{m}$. 
Kennedy-Kirrama Road, 27 km WNW of Cardwell, $620 \mathrm{~m}$, on streamside trees, Pócs \& Streimann 99121/O; Kirrama Range, Flat Creek along Kennedy-Kirrama Road, 25 km WNW of Cardwell, $700 \mathrm{~m}$, submontane rainforest in gully, Pócs \& Streimann 99122/T; Broadwater, Abergowrie State Forest, $34 \mathrm{~km} \mathrm{NW}$ of Ingham, $28 \mathrm{~m}$, in waterlogged lowland rain forest with many palms and giant buttressed Ficus albipila and F. superba, Pócs \& Streimann 99125/W; Cardwell Range, Kirrama State Forest, SE slopes above Kennedy, $185 \mathrm{~m}, 18^{\circ} 11.7^{\prime} \mathrm{S}, 145^{\circ} 52.1^{\prime} \mathrm{E}$, in relatively dry lowland rainforest, T. Pócs, A. Cairns \& E.A. Brown \& Ch. Cargill 01098/Q; Paluma Range National Park, Camp Creek, 765 m, in wet montane rainforest along creek. T. Pócs, A. Cairns \& E.A. Brown \& Ch. Cargill 01118/J; Birthday Creek, James Cook University experimental area, 840-870 $\mathrm{m}$, in wet montane rainforest. T. Pócs, A.Cairns \& E.A. Brown \& Ch. Cargill 01121/BK; Paluma Dam forestry road, $1.6 \mathrm{~km} \mathrm{~N}$ from Paluma-Ewan Road, $880 \mathrm{~m}$, at montane rainforest edge, $S$. \& T. Pócs, A. Cairns \& E.A. Brown \& Ch. Cargill 01122/X.

Distribution. NSW, QLD. Hitherto known only from Southeast Asia: Japan, Vietnam, Malaysia and Cambodia.

IlluStRATiOn: Tixier (1981: 59, fig. 4).

In his review of the very variable Cololejeunea floccosa, Tixier (1981) noted that the distinction between this species and Cololejeunea amoena Benedix (1953) was not well established, and Söderström et.al. (2010) repeated this doubt about C. amoena as a separate species. It was distinguished by Benedix against C. floccosa by its different perianth shape, the large, pearl-shaped papillae on its lobe and keel, and by its smaller, not inflated sock cell at the lobule base. Tixier (1981) found that the Japanese and Indochinese populations have transitional characters between the two taxa, with their large, pearl-shaped papillae on the lobe but not on the carina and sometimes with an inflated sock cell at the lobule base, and named it Cololejeunea floccosa var. amoenoides. It should be investigated whether this is synonymous with Cololejeunea subfloccosa Mizutani, 1984: 168. On the subtropical and tropical east coast of Australia this transitional variety seems to be widespread. On this basis the species rank of Cololejeunea amoena is not tenable and can be considered here as a variety of Cololejeunea floccosa:

Cololejeunea floccosa (Lehm. \& Lindenb. in Lehm.) Schiffn. var. amoena (Benedix) Pócs, stat. nov.

BAsionym: Cololejeunea amoena Benedix, Feddes Repert. Spec. Nov. Regni Veg. Beih. 134: 25. 1953.

Distribution. Bangladesh, Sri Lanka (Södertröm ex litt.), Philippines, Malaysia, Indonesia: Java (Benedix 1953; Zhu \& So 2001).

33c. Cololejeunea floccosa var. fraseriana Pócs, var. nov. (see above)

All specimens are known from southern Queensland (Fraser Island, Great Sandy National Park), where it seems to be endemic, as is Cololejeunea heinari Pócs.

\section{DisTRIBUTION. QLD.}

Cololejeunea floccosa is very variable. In his revision, Tixier (1981) distinguished 8 varieties on the basis on morphology, to which var. amoena and var. fraseriana should be added. Molecular investigation may reveal cryptic species within its worldwide distribution.

\section{Cololejeunea inflata Steph.}

Hedwigia 34(5): 249. 1895.

Cololejeunea oshimensis (Horik.) Benedix, Feddes Repert. Spec. Nov. Regni Veg. Beih. 134: 42, 1953.

Hitherto only one record, without a vouchered specimen, was known from Australia (Meagher 2003: Queensland, Mt. Lewis), although Renner (2011) suggested that this might have been a misidentification. From our collections several new localities became known in Queensland: Paluma Range National Park, Birthday Creek (James Cook University experimental area), 850-870 m, $18^{\circ} 59.9^{\prime} \mathrm{S}, 146^{\circ} 11^{\prime} \mathrm{E}$ and Camp Creek, $765 \mathrm{~m}$, in montane rainforest ('complex nothophyll vine forest') along streamlet, Pócs, Cairns \& Streimann 9972/F, S. \& T. Pócs, A. Cairns, E.A. Brown 
\& Ch. Cargill 01118/D \& E; Atherton Tableland, Cardwell Range, on E slope of Mt. Fisher (extinct volcano), $9 \mathrm{~km}$ NE of Ravenshoe, 940-1000 m, in disturbed submontane rainforest, Pócs \& Streimann 99114/W; along the Butchers Creek-Topaz Road, $27 \mathrm{~km}$ SE of Atherton, $780 \mathrm{~m}$, degraded remnants of submontane rainforest, Pócs \& Streimann 99116/J; Kirrama Range, Flat Creek along Kennedy-Kirrama Road, 25 km WNW of Cardwell, $700 \mathrm{~m}$, disturbed submontane rainforest in gully, Pócs \& Streimann 99122/M; Broadwater State Forest Park 34 km NW of Ingham, 28 m, in waterlogged lowland rain forest with many palms and giant buttressed Ficus albipila \& F. superba, Pócs \& Streimann 99125/Y; Bellenden Ker Range, Wooroonooram National Park, summit ridge $\mathrm{W}$ of Centre Peak, 1520-1560 m, in elfin forest rich in epiphytes, S. \& T. Pócs, A. Cairns, E.A. Brown \& Ch. Cargill 01091/BF; Cardwell Range, Kirrama State Forest along Douglas (Curran) Creek, at N side of Mt. Pershouse, 680-700 m, in relatively open montane rainforest.

Distribution. QLD. Indomalesian species known from Sri Lanka to New Caledonia (Zhu \& So 2001).

Illustrations: Benedix [1953: t. 11 as Cololejeunea oshimensis (Horik.) Benedix], Zhu \& So (2001: 350, f. 131), Tixier (1979: 741, f. 11).

\section{Cololejeunea ocelloides (Horik.) Mizut.}

J. Hattori Bot. Lab. 24: 277. 1961.

Cololejeunea leonidens Benedix, Feddes Repert. Spec. Nov. Regni Veg. Beih. 134: 42. 1953.

LiteratURe ReCORDS: Thiers (1988: 143), Scott (1997: 107), Bolin \& Henderson (2002: 224), McCarthy (2003: 32).

This species is often confused with Cololejeunea ocellata (Horik.) Benedix, Feddes Repert. Spec. Nov. Regni Veg., Beih. 134: 38, 1953. In Cololejeunea ocelloides the leaves are somewhat falcate, and the second lobule tooth is much larger than the first tooth which bears the hyaline papilla on its proximal side. In Cololejeunea ocellata the leaves are not falcate, the two lobule teeth are subequal, parallel or crossing each other, and the hyaline papilla is on the inner surface of the base of the first lobule tooth. The much larger, pyriform, entally hanging hyaline papilla well distinguishes this species from C. ocelloides (Zhu \& So 2001). The species is well illustrated by Horikawa (1934), Mizutani (1984) and Thiers (1988).

In Queensland the species is not rare.

New localities: Mt. Fisher, Cardwell Range, $9 \mathrm{~km} \mathrm{NE}$ of Ravenshoe, $980 \mathrm{~m}$, in disturbed tropical forest with vigorous regrowth, H. Streimann 64793, 30.04.2000; Atherton Tableland, Main Coast Range, Mt. Lewis, near summit along forest road, $56 \mathrm{~km} \mathrm{NNE} \mathrm{of}$ Mareeba,1200-1240 m, montane rain forest on gentle slope, with small boulders, Pócs \& Streimann 99111/AJ.

Distribution. QLD. Malesian species known from Sumatra to New Guinea (Pócs \& Piippo 2011).

Illustrations: Horikawa (1934: 280, fig. 60), Benedix (1953: t. 10 sub Cololejeunea leonidens Benedix), Tixier (1969: 576, fig. 17 sub Cololejeunea leonidens), Mizutani (1984: 162, fig. 4), Thiers (1988: 145, pl. 13: 1-5).

36. Cololejeunea peraffinis (Schiffn.) Schiffn.

Consp. Hepat. Arch. Ind.: 245. 1898.

Literature ReCORDS: Thiers (1988: 144), Piippo (1994: 54), Scott (1997: 104), Pócs \& Streimann (1999: 169), Bolin \& Henderson (2002: 224), McCarthy (2003: 224).

DisTRIBUTION. QLD. Widespread Palaeotropical species from Africa through Indomalesia to New Guinea and New Caledonia (Pócs \& Piippo 2011).

ILlustrations: Benedix (1953: t. 9), Tixier (1988: 443, fig. 8), Thiers (1988: 591, pl. 13: 6-9).

37. Cololejeunea pseudofloccosa (Horik.) Benedix Feddes Repert. Spec. Nov. Regni Veg. Beih. 134: 36. 1953.

Literature RECORDS: Pócs \& Streimann (1999: 169), McCarthy (2003: 33).

Notes. Only two records were known before from Queensland. The following are new localities: Atherton Tableland. Mt. Baldy, $4 \mathrm{~km}$ WSW of Atherton, $1060 \mathrm{~m}$, in old Araucaria cunninghamii and Acacia melanoxylon plantation intermixed with trees of montane rainforest regrowth, Pócs \& Streimann 99108/AS; Hugh Nelson Range. Summit around telecommunication tower, $22 \mathrm{~km} \mathrm{~S}$ of Atherton, $1240 \mathrm{~m}$, somewhat disturbed montane rainforest dominated by large 
Acacia and Alphitonia, Pócs \& Streimann 99109/ $B E$; Atherton Tableland. Main Coast Range. Mt. Lewis, $49 \mathrm{~km}$ NNE of Mareeba, $1050 \mathrm{~m}$, grazed opening with small trees in swampy area of disturbed submontane rainforest, Pócs \& Streimann 99113/S; Bellenden Ker Range in Wooroonooram National Park. Summit ridge W of Centre Peak, 1520-1560 m, in elfin forest rich in epiphytes, $S$. \& T. Pócs, A. Cairns, E.A. Brown \& Ch. Cargill 01091/BH; Paluma Range. Crystal Creek National Park. N of Paluma, on ridge leading to Witt's Lookout, 930-950 m, in montane rainforest, $S$. \& T. Pócs 0113/E.

Distribution. QLD. Very rare in the Neotropics (Brazil) but widespread in tropical Asia and Australia; reported also from New Guinea (Pócs \& Streimann 1999).

Illustrations: Benedix (1953: t. 9: h-k), Jones (1968: 570, fig. 4b), Tixier (1969: 560, fig. 8), Zhu \& So (2001: 361, fig. 135), Asthana \& Srivastava (2003: pl. 45).

\section{Cololejeunea verrucosa Steph.}

Figs $25 \& 26$

Hedwigia 34(5): 253. 1895.

Notes. New for Australia: Queensland, Cape Tribulation area, Gap Creek. $38 \mathrm{~km} \mathrm{~S}$ of Cooktown, $8 \mathrm{~km} \mathrm{SW}$ along the Rossville-Bloomfield River Road, near Cedar Bay, 200 m, lowland rainforest along rocky streambed, Pócs \& Streimann $99104 / J$. The species is distinguishable by the compound, rosette-like dorsal papillae of the leaf lobe, like $C$. verdoornii (S. Hatt.) S. Hatt. but differing from it by its hooked first lobule tooth with marginal hyaline papilla, as in Cololejeunea floccosa (Lehm. \& Lindenb. in Lehm.) Schiffn. (Mizutani 1975, 1976; Zhu \& So 2001). The Australian specimens have a more developed vitta, up to $4(-5)$ cells long, but in other characters agree well with the type of $C$. verrucosa.

Distribution. QLD, widespread Malesian species known from Java through Southeast Asia to the Solomon Islands (Mizutani 1976; Zhu \& So 2001).

Illustrations: Hattori (1941: 334, t. CXXII sub Taeniolejeunea nakaii S. Hatt.), Zhu (1995: 106, fig. 15).

\section{DUBIA AND EXCLUDENDA}

Cololejeunea microscopica (Taylor) Schiffn.

Hepat. (Engl.-Prantl): 122, 1893.

BASIONYM: Jungermannia microscopica Taylor, Mackay, F1. Hibern. 2: 59. 1836.

Cololejeunea tortifolia Steph., Bih. Kongl. Svenska Vetensk.-Akad. Handl. 26(3, 6): 65. 1900, syn. nov. Chile, Corral, Dusén, 1896. I investigated the type of Cololejeunea tortifolia Steph. (NY-00512615) and identified it as Aphanolejeunea microscopica, now Cololejeunea microscopica (Taylor) Schiffn. This species probably does not occur in Australia and may be confused with Cololejeunea papillosa (K. I. Goebel) Mizut.

Physocolea tortifolia Steph., Spec. Hepat. 5: 885. 1916.

LiterATURE RECORDS: McCarthy (2003: 33), indicated from Queensland.

\section{Key to the Australian SUbGEnera AND SPECIES OF Cololejeunea (SPRUCE) STEPH.}

Terms used to describe the size of plants are defined according to shoot width, as minuscule (below $0.6 \mathrm{~mm}$ width), small $(0.6-0.9 \mathrm{~mm})$, medium size $(0.9-1.2 \mathrm{~mm})$, large (1.2-2.3 mm) and robust (above $2.3 \mathrm{~mm}$ width). The traditional subgenera of Cololejeunea are based on morphological characters which in many cases (e.g., hyaline margin) can be mere homoplasy (Yu et al. 2013). Nevertheless, these classic subgenera, although artificial, are useful tools in grouping and identification of species.

1. Minuscule to small, epiphyllous plants often with athecal branching, often heterophyllous, leaves distant, fully developed leaves with urn-shaped or inflated lobule which exceeds half of lobe length. The species with uniform leaves have a reduced lobule not more than 10 cells wide on average. Stylus not observed. ................... 2

1. Mostly small to large-size plants, always with thecal Lejeunea-type branches. Leaves distant to imbricate, almost always consisting of lobe and much shorter lobule, the lobule usually wider than 10 cells. Stylus in most species visible, at least at apex of juvenile shoots. Disciform gemmae develop on surface of lobe. ..................... 3

2. Minuscule, whitish, heterophyllous plants, leaves distant, the Australian species with rounded apex. Leaves either fully developed, lobulate, or the 
lobule is reduced to a narrow strip, or the leaves are rudimentary, reduced to a small, 1-4-cell-wide lamina. First lobule tooth usually unicellular. Discoid gemmae develop on lobe margin. ........ .............. Subg. I. Aphanolejeunea

2. Minuscule to small plants. Both athecal basiscopic and thecal Lejeunea-type branches can occur. Leaves uniform, lanceolate, distant to contiguous, either elobulate (or with a lobule reduced to $1-3$ cells), sometimes only female bracts have lobules, in other cases most leaves are uniformly lobulate. First lobule tooth usually bicellular. The Australian species have acute or apiculate apices. Lobe margin often denticulate. Discoid gemmae can occur also on lobe surface. ............ ............... Subg. IV. Diaphanae

3. Leaf lobe cells papillate or mamillate on most of their dorsal surface. ................. 4

3. Leaf lobe cells smooth, without any protuberances on most of their surface. ............. 5

4. Small to medium-sized, whitish or yellowish green plants with leaf cells smaller than $12 \mu \mathrm{m}$ on average, with evenly thickened walls and with round, blunt papilla, usually with well-delimited vitta with large cells of different content. Perianth compressed. ...... Subg. VII. Taeniolejeunea

4. Leaf margin \pm acutely dentate. Lobe cells generally larger, with distinct, acute papilla. Plants usually green. Average leaf cells larger, leaf without any well-delimited vitta. Perianth inflated with 4-5 subequal keels. ...... . Subg. II. Cololejeunea

5. Leaf lobe in most cases margined by sharply delimited, shiny hyaline cells, or at least the lobe has a hyaline apex. If not, lobule is ligulate, mitten-shaped or saccate with three lobular teeth. ............ .............. Subg. VI. Pedinolejeunea

$5^{*}$ Leaf lobe without hyaline margin or hyaline apex. Lobule with $1-2$ teeth. ............... 6

6. Mostly green or pale green, dull or somewhat glossy plants of various sizes. Lobe with entire, denticulate or dentate margin, ovate, lobule less than half of lobe length, flat or inflated, margin not involute. Mostly epiphyllous. ...........

. Subg. V. Leptocolea

6. Large or robust plant with yellowish brown color and silky shine. Lobe entire. Lobule half or more of lobe length, with strongly involute margin except for 1-2 outstanding, filiform, erect teeth. Mostly on twigs but also on leaves. .............

\section{Subg. I. Aphanolejeunea}

1. First (distal) lobule tooth falcate, pointing sideways. .................. 2

1. First lobule tooth claviform, straight, pointing forward. ........... 3. Cololejeunea thiersiae

2. Lobe much (about 4 cells) longer than lobule, apex acute to obtuse. .... 1. Cololejeunea sintenisii

2* Lobe hardly (1-2 cells) longer than lobule, with truncate, rounded or obtuse apex ....... 3

3. Lobe of lobulate leaves $100-125 \mu \mathrm{m}$ (7-12 cells) long, often with perforated apex. Lobule $40-60 \mu \mathrm{m}$ (6-10 cells) wide, with \pm isodiametric cells. . . . . . ................. C. Cololejeunea veillonii

3. Lobe of lobulate leaves $130-180 \mu \mathrm{m}$ (10-13 cells) long, apex never perforated, lobule 70-80 $\mu \mathrm{m}(10-14$ cells) wide, lobule cells \pm elongate, often sigmoid.

\section{Cololejeunea papillosa}

\section{Subg. II. Cololejeunea}

1. Small plants, shoot $0.5-0.8 \mathrm{~mm}$ wide, leaf margin entire or denticulate. . . . . . . . . . . 2

1. Medium-size plants, shoot $0.8-1.2 \mathrm{~mm}$ wide, leaf margin acutely dentate, length of at least some teeth equaling or exceeding cell width. ......... 3

2. Lobe triangular ovate, lobule with only one normal tooth, the second reduced or obsolete, hyaline papilla ental, lobule cells uniform. .....

6. Cololejeunea mamillata

2* Lobe falcate-ovate, lobule with two teeth with hyaline papilla between them, leaf base with vitta-like cells. . . . . . . . 8. Cololejeunea tenella

3. Lobe margin with acute teeth much longer than wide. Lobule teeth \pm equal, unicellular, acute, crossing each other. ........... 5. Cololejeunea haskarliana

3. Lobe margin with obtuse teeth equaling their width. Lobule teeth unequal, the first tooth acute, bicellular, much longer than the second unicellular or obsolete tooth. ........... 7. Cololejeunea schmidtii

\section{Subg. III. Cryptolejeunea}

1. Only one species occurs in Australia: ......... .............. 9. Cololejeunea inflectens

\section{Subg. IV. Diaphanae}

1. Lobules of fully developed leaves very much inflated, utriculate, their free margin strongly inrolled with usually invisible teeth, other leaves have reduced lobule with one tooth. ................ 10. Cololejeunea amphibola 
1. Lobules slightly inflated, never utriculate. . . . 2 2

2. Leaves ovato-lanceolate with acute or longly acuminate apex. Lobule $0.1-0.4$ of lobe length, often reduced. Usually grows on decaying wood. ....

13. Cololejeunea wightii

2* Leaves lanceolate with acute or obtuse apex. Lobule on well-developed leaves $1 / 3-1 / 2$ of lobe length. .................... 3

3. Perianth pyriform with 5 narrow, blunt carinae with round apex. Female bracts with narrow lanceolate lobule without prolonged apical tooth. ......... .............. 11. Cololejeunea diaphana

3. Perianth pyriform with 5 wide, sharp carinae ending in blunt apex. Lobule of female bracts with a 4-cell-long filiform tooth. .... 12. Cololejeunea iwatsukiana

\section{Subg. V. Leptocolea}

1. Style at leaf base filiform, 3-4(-7) cells long. All lobe cells smooth, except marginal cells can sometimes be slightly papillose. . . . 19. Cololejeunea trichomanis

1. Style at leaf base unicellular (rarely bicellular), part of outer lobe cells sometimes with small papillae. ... 2

2. Median lobe cells elongate, more than $30 \mu \mathrm{m}$ long, with intermediate thickenings. . . . . . . . 3

2. Median lobe cells smaller, less than $30 \mu \mathrm{m}$ long, without intermediate thickenings. . . . . . . 4

3. Leaf broad ovate, lobule lanceolate-ovate, gemmae with 4 adhesive cells, female bracts much shorter than perianth. ...... 15. Cololejeunea gottschei 3. Leaf lanceolate, \pm falcate, lobule narrow lanceolate, gemmae with 3 adhesive cells, female bracts \pm equaling perianth length.

\section{Cololejeunea longifolia}

4. All lobe cells smooth, without papillae. Part of lobe bordered by quadrangular, elongate cells parallel to margin. Perianth cordate, compressed, with two wings, ventrally bulging but without ventral plicae. First lobule tooth bicellular, second tooth obsolete. ........ 16. Cololejeunea heinari

4. Some of marginal lobe cells covered by small papillae or at least the margin is denticulate, without elongate, quadrangular cells. Perianth inflated with two ventral plicae. ............... 5

5. More than $60 \%$ of dorsal lobe surface covered by small, conical papillae. Lobule with two teeth, the first usually bicellular. Perianth acutely papillose . . ................ 18. Cololejeunea obliqua

5. Lobe surface smooth except for some marginal or submarginal cells which can have small papillae. Lobule usually with one prominent bicellular tooth, the second one obsolete, round or triangular. Perianth minutely papillose. ........ 14. Cololejeunea cordiflora

\section{Subg. VI. Pedinolejeunea}

1. Leaf border without hyaline cells. Lobe cells always with smooth cuticle. ............... 2

1. Leaf bordered by hyaline margin consisting of 1-3 rows of cells without chloroplasts, or at least hyaline cells at leaf apex present. Median lobe cells with smooth or punctate cuticle. ........... 3

2. Leaf lobule ligulate, mitten-shaped with two blunt, unequal segments. Hyaline papilla, if present, is at lobule apex. .... 26. Cololejeunea raduliloba

2. Leaf lobule broadly ovate, flat, with (2-)3 subequal, bicellular teeth. Hyaline papilla at proximal side of first tooth. ................ $\ldots \ldots \ldots \ldots \ldots$ 22. Cololejeunea laevigata

3. Stylus filiform, up to $200 \mu \mathrm{m}$ long, consisting of 4-9 uniseriate cells. Hyaline margin restricted to distal half of lobes, consisting of quadrangular cells with smooth margin. ................. 4

3. Stylus short, ovate, unicellular or rarely bicellular.

........................... 5

4. Cuticle punctate. Lobule oblong, 4-6 times as long as stem width, second lobule tooth elongate, acute, somewhat falcate. Stylus of female bracts 2 cells wide at base. . . . 29. Cololejeunea vidaliana

4. Cuticle smooth. Lobule ovate, 2-3 times as long as stem width, second lobule tooth blunt. Stylus of female bracts one cell wide at base ........ $\ldots \ldots \ldots \ldots \ldots$ 27. Cololejeunea stylosa

5. Hyaline cells only at apical part of leaf lobe, fingershaped, forming small fimbriate-margined group on lobe apex. Lobule ovate, inflated, with larger first tooth and triangular or obsolete second tooth. .... . . . . . . . . . 20. Cololejeunea cardiocarpa

5. Hyaline cells all around or on greater part of lobe margin, rectangular, forming smooth margin. ...6 6 6. Lobules mostly ligulate or lanceolate, flat. . . 7 6. Most lobules ovate to oblong, often inflated, uni-, bi- or tridentate, or both ovate and ligulate lobules occur on the same specimen. ......... 8

7. Leaves orbicular. Lobe with single hyaline margin. Most lobules lanceolate without side tooth. ...... .............. 25. Cololejeunea maritima

7. Leaves asymmetrically ovate to subelliptical. Lobe often bordered by 2-3 rows of hyaline cells. Most lobules narrow ligulate or lanceolate with blunt tooth on their proximal margin. 
8. All leaves with ovate or oblong, inflated lobules. Hyaline papilla lateral or ental ........9

8. Leaves with ovate, triangular and ligulate lobules occur on the same specimen. Ventral edge of lobe without hyaline margin. Hyalina papilla developed on apex of lobule or lobule tooth ......... ... . . . . 25. Cololejeunea planissima

9. Lobule ovate, usually with two teeth, the first bicellular, the second small, triangular, unicellular. Perianth cordate, flattened, without ventral plicae. . ... . . . . . . . . 21. Cololejeunea kapingaensis

9. Lobule cuneate with truncate, tridentate apex. Median tooth larger, with hyaline papilla on proximal side. Perianth cordate, compressed, with two ventral plicae. . . . . . . . 28. Cololejeunea triapiculata

\section{Subg. VII. Taeniolejeunea}

1. Lobe with hyaline margin formed by 2-3 rows of translucent, smooth cells and vitta of 1-2 rows of ocelli. The two small lobule teeth do not cross each other. Hyaline papilla ental, at inner base of first tooth. . . . . . . . . 34. Cololejeunea inflata

1. Lobe not bordered by hyaline cells. Marginal cells small, similar to the majority of lobe cells, containing chlorophyll. Papillae present, which can cause slight denticulation of margin. . . . . . . . . 2

2. Lobe without true vitta. Group of larger basal cells present, gradually merging with smaller lobe cells. Larger basal cells also contain chloroplasts. . . . 3

2 . Lobe with true vitta formed by idioblasts in one or more rows, cells containing one large oil body and sharply delimited from neighboring smaller lobe cells. ..................4 4

3. Two lobule teeth cross each other, as in C. peraffinis and $C$. ocelloides. Hyaline papilla ental, hanging at inner side of base of first tooth. . . . . . . . . . . . . . . . . . . . 37. Cololejeunea pseudofloccosa

3* Single falcate tooth developed, the second obsolete or absent, as in Cololejeunea floccosa var. floccosa. Hyalina papilla erect at proximal side of first tooth. . . . . . 32c. Cololejeunea floccosa var. fraseriana

4. Lobule with two short, equal, \pm parallel teeth with hyaline papilla between. ..........5

4. Lobule with two unequal teeth, the first usually shorter than the second, mostly crossing each other. .................. 6

4.* Lobule with only one well-developed falcate tooth, the second tooth short-triangular, obsolete or absent. Vitta formed by one row of 4-8 cells, often with second row of smaller vitta cells. ..... 9
5. Leaf asymmetrically ovate with straight ventral margin, vitta formed by one row of 4 ocelli, second lobule tooth usually unicellular. . . . . . . . . . . ............ 30. Cololejeunea appressa

$5^{*}$ Leaf falcate-ovate with arched ventral margin, vitta formed by 2-3 rows of 5-6 ocelli, second lobule tooth 1-2 cells long. . . . 32. Cololejeunea falcata

6. Lobule with compound, stellate papillae (under high magnification), vitta uniseriate, 3-5 cells long. . . . . . . . 38. Cololejeunea verrucosa 6. Lobule with simple, rounded or acute papillae. . . $\ldots \ldots \ldots \ldots \ldots \ldots \ldots \ldots$

7. Lobe falcate, lobule elongate, flask-shaped, widest near its base, vitta uniseriate, perianth flat, without ventral plicae. . . . . 31. Cololejeunea cairnsiana

7. Lobe broadly ovate, lobule ovate, inflated, widest at its middle, vitta $1-3$-seriate. . . . . . . . . 8

8. Lobe keel and perianth prominently papillose, lobule teeth not always crossing each other. hyaline papilla ental, on inner surface of base of first tooth, autoicous. . . . 36. Cololejeunea peraffinis

8* Lobe keel and perianth smooth, dorsal lobe surface with small papillae, lobule teeth always crossing each other, hyaline papilla only partly covered by first tooth, synoicous.

35. Cololejeuna ocelloides

9. Papillae on lobe surface small, $1-3 \mu \mathrm{m}$ in diameter, dotlike. Sock cell at stylus base inflated. Vitta smooth. . . . . . . 33a. Cololejeunea floccosa var. floccosa

9. Papillae on lobe surface much wider, $4-8 \mu \mathrm{m}$ of diameter, pearl-like. Sock cell at stylus base sometimes inflated. Some vitta cells with low papillae. . . . . . . . . . . 33b. Cololejeunea floccosa var. amoenoides 9.*Papillae on lobe surface 4-8 $\mu \mathrm{m}$ wide, pearl-like. Sock cell at stylus base not inflated. Vitta strongly papillose. (Until now not observed in Australia). . .

33d. Cololejeunea floccosa var. amoena

\section{PhytogeographicAl CONCLUSIONS}

The composition of the Cololejeunea flora of Australia reflects tropical rather than southern temperate influences, as its temperate part has few species of the genus. Only two species are known from Tasmania and Victoria states, whereas eight species and one variety are already known from the subtropical part of New South Wales, while the largest concentration of Cololejeunea taxa falls within tropical Queensland with 35 species 
and two varieties. The species can be grouped in the following distribution types (Fig. 33):

Endemic to Australia (all in Queensland), 4 species (10.5\%): Cololejeunea cairnsiana, C. heinari, C. iwatsukiana, C. thiersiana.

Indomalesian, 7 species (18.5\%): C. gottschei, C. inflata, C. maritima, C. ocelloides, C. tenella, C. triapiculata, C. trichomanis.

Indomalesian, extending to the Pacific, 5 species (13\%): C. amphibola, C. cordiflora, C. longifolia, C. stylosa, C. veillonii.

Indomalesian, extending both to the Pacific and East African islands, 4 species (10.5\%): C. falcata, C. haskarliana, C. infelctens, C. raduliloba.

Pacific species reaching Australia, 1 species (2.6\%): C. kapingaensis.

Southeast Asian (mostly Japan, China, Indochina), 2 species (5.3\%): C. schmidtii, C. verrucosa.

American-Asian bicontinental, 1 species $(2.6 \%)$ : C. papillosa.

Palaeotropical, 3 species (7.9 \%): C. floccosa, C. peraffinis, C. vidaliana.

Pantropical, 9 species (23.7\%): C. appressa, C. cardiocarpa, C. diaphana, C. lanciloba, C. obliqua, C. planissima, C. pseudofloccosa, C. sintenisii, C. wightii.

Southern temperate, 2 species (5.2\%): C. laevigata (Australasian), C. mamillata (Australasia + South America)

When these figures are compared with those of Western Melanesia and the Fiji Islands (Piippo 1994; Pócs 2012), the high proportion of Indomalesian (42\%) and Pantropical elements (23.7\%), and the relatively small number of endemics as compared to the vascular flora of Australia, are conspicuous. This is probably due to the former land connection between New Guinea and Australia. This land connection existed as early as the lower Cretaceous (Barremian age, $125 \mathrm{Ma}$ ) through the Tertiary, when the first magnolioid angiosperms and cryptogams could also gradually penetrate from the northeast through the land bridge (Durham 1963; Dettmann 1994). As the first extant Lejeuneaceae lineages only started to evolve during the mid-Cretaceous, and the epiphyllous

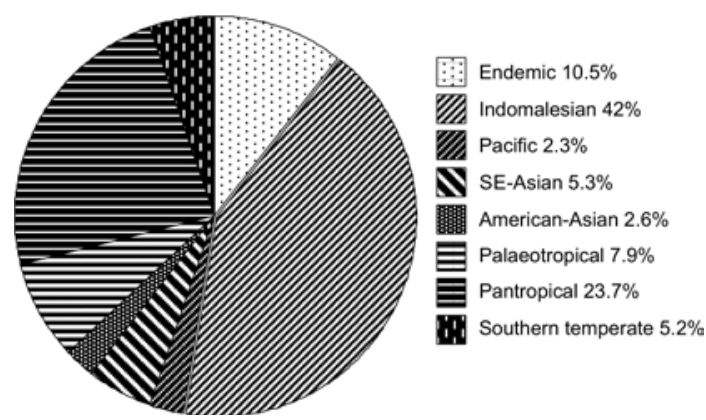

Fig. 33. The distribution types of Australian Cololejeunea flora.

genera such as Cololejeunea during the Eocene (Wilson et al. 2007; Feldberg et al. 2014), they had the opportunity to cross over this land bridge step by step. Although the large green protonematal spori of forest-inhabiting Lejeuneaceae are not desiccation-resistant, the abundant development of gemmae in Cololejeunea species could have made air dispersal possible (Zanten \& Pócs 1981). The survival potential of these discoid gemmae has not been studied so far. More recent dispersal across the Torres Strait by birds or bats is also a possibility.

ACKNOWLEDGEMENTS. I am greatly indebted to the late Heinar Streimann (CANB), the late Elizabeth A. Brown, Robert G. Coveny (NSW), and Andi Cairns (JCT) for taking me to the rich habitats of the eastern parts of Australia in 1999, 2000 and 2001, and to my wife, Sarolta Pócs, and Christine D. Cargill (CANB) for their kind help as co-collectors during those journeys. I thank the Australian Biological Resources Study Participatory Program for sponsoring the collecting trips, the Hungarian Natural History Museum (BP) for the use of its Hitachi S-2055 N scanning electron microscope, and especially Krisztina Buczkó for her help in its operation. I am grateful to the reviewers, David Meagher and Lars Söderström, for their linguistic corrections, helpful comments and useful additions to the manuscript of this paper.

\section{REFERENCES}

Allorge V. \& Jovet-Ast S. 1950. Aphanolejeunea teotonii nov. sp., Hépatique des Açores. Rev. Bryol. Lichénol. 19: 19-24.

Asthana G. \& Alam A. 2013. Cololejeunea clavatopapillata Steph. - New to Asia. Trop. Bryol. 35: 39-42. 
Asthana G. \& Srivastava S. C. 2003. Indian Cololejeunea. A taxonomic study. Bryophyt. Biblioth. 60: 1-155.

Benedix E. H. 1953. Indomalayische Cololejeuneen. Eine Revision tropischer Lebermoose. Feddes Rep. Spec. Nov. Beih. 134: $1-88+$ t. $1-31$.

Bolin A. \& Henderson R. J. F. 2002. Plantae - liverworts and hornworts. In: R. J. F. Henderson (ed.), Names and distribution of Queensland plants, algae and lichens, pp. 222-227. Queensland Herbarium, Brisbane.

Chantanaorrapint S. \& Pócs T. 2014 Southern Thailand bryophytes I, with description of Cololejeunea ramronensis. In: D. Telnov (ed.), Biodiversity, biogeography and nature conservation in Wallacea and New Guinea. 2: 113-122. Entomological Society of Latvia, Riga.

Dettmann M. E. 1994. Cretaceous vegetation: the microfossil record. In: R. S. Hill (ed.), History of the Australian Vegetation: Cretaceous to Recent, pp. 143-170. Cambridge University Press, Cambridge.

Durham J. W. 1963. Plaeogeographic conclusions in light of biological data. In: J. L. GRisitT (ed.), Pacific Basin Biogeography, pp. 355-365. Bishop Museum Press, Honolulu.

Eggers J., Infante M. \& Heras P. 2004. New bryophyte records from tropical countries 5. Trop. Bryol. 25: 19-23.

Feldberg K., Schneider H., Stadler T., SchäFer-Verwimp A., Schmidt A. R. \& HeinRIChs J. 2014. Epiphytic leafy liverworts diversified in angiosperm dominated forests. Scientific Reports 4(5974): 1-6.

Hattori S. 1941. Taeniolejeunea nakaii S. Hattori. Iconogr. Pl. Asiae Orient. 4(2): 379-382, pl. 122.

Hattori S. \& Noguchi A. 1954. Bryophytes of Aoshima Island. In: Natural History of Aoshima, pp. 63-66, f. 1-21. Miyazaki (in Japanese).

Herzog T. 1932. Neue Hepaticae aus der weiteren Indomalaya. Ann. Bot. 5: 83-98.

Herzog T. 1950. Hepaticae Borneenses (Oxford University Expedition to Sarawak, 1932). Trans. Brit. Bryol. Soc. 1: 275-326.

Horikawa Y. 1931. Studies on the Hepaticae of Japan. V. J. Sci. Hiroshima Univ., Ser.B, Div.2, Bot. 1: 55-76.

Horikawa Y. 1934. Monographia Hepaticarum Australi-Japonicarum. J. Sci. Hiroshima Univ. Ser. B, Div. 2, Bot. 2: 101-325.

Hürlimann H. 1987. Hepaticae aus dem Gebiete des südlichen Pazifik IX. Bauhinia 8(4): 221-234.

INFANTE M. \& HeRAS P. 1999. Bryophytes from the Republic of Equatorial Guinea (West Central Africa). VI. Cololejeunea iradieri sp. nov., Cololejeunea magna stat. nov. and their relations to similar species. Trop. Bryol. 17: 13-18.

Jones E. W. 1957. African hepatics. XII. Some little-known Lejeuneaceae. Trans. Brit. Bryol. Soc. 3: 191-207.

Jones E. W. 1968. African hepatics. XX. Some little-known species and some extensions of range. Trans. Brit. Bryol. Soc. 5(3): 563-572.

Marline L., Andriamiarisoa R. L., Bardat J., ChuahPetiot M., Hedderson T. A. J., Reeb C., Strasberg D., Wilding N. \& Ah-Peng C. 2012. Checklist of the bryophytes of Madagascar. Cryptog. Bryol. 33(3): 199-255.

McCarthy P. M. 2003. Catalogue of Australian liverworts and hornworts. Flora of Australia Supplementary Series 21. Australian Biological Resources Study, Canberra.

McCARThy P. M. 2006. Checklist of Australian Liverworts and Hornworts. Australian Biological Resources Study, Canberra. Version 6 April 2006. http://www.anbg.gov.au/ abrs/liverwortlist/liverworts_a_z.html

Meagher D. 2003. New and interesting bryophyte records. Australas. Bryol. Newsl. 48: 8-9.

Miller H. A. 1956. Cryptogams of Kapingamarangi atoll, Caroline Islands I. Bryophyta. Bryologist 59: 167-173.

Miller H. A., Whittier H. O. \& Bonner C. E. B. 1963. Bryoflora of the atolls of Micronesia. Nova Hedwigia Beih.. 11: 1-89.

Mizutani M. 1961. A revision of Japanese Lejeuneaceae. J. Hattori Bot. Lab. 24: 115-302.

Mizutani M. 1965. Studies of little known Asiatic species of Hepaticae in the Stephani Hebarium 2. On some little known Southeast Asiatic species of the genus Cololejeunea. J. Hattori Bot. Lab. 28: 107-121.

Mizutani M. 1975. Epiphyllous species of Lejeuneaceae from the Philippines. J. Hattori Bot. Lab. 39: 255-262.

Mizutani M. 1976. Studies of little known Asiatic species of Hepaticae in the Stephani Hebarium 9. Some little-known species of the family Lejeuneaceae. J. Hattori Bot. Lab. 40: $441-446$.

Mizutani M. 1984. Notes on the Lejeuneaceae. 8. Japanese species of the subgenus Taeniolejeunea of the genus Cololejeunea. J. Hattori Bot. Lab. 57: 153-170.

O’Shea B., Eggers J., Pursell R. A., Sollman P. \& StevenSON C. R. 1997. New bryophyte taxon records for tropical countries 1. Trop. Bryol. 13: 175-183.

PIIPPO S. 1994. On the bryogeography of Western Melanesian Lejeuneaceae, with comments on their epiphyllous occurrence. Trop. Bryol. 9: 43-57.

Pócs T. 1984. New or little known epiphyllous liverworts, III. The genus Aphanolejeunea Evans in tropical Africa. Cryptog. Bryol. Lichénol. 5: 239-267.

Pócs T. 1994. New or little known epiphyllous liverworts, V. Aphanolejeunea collected by Barbara M. Thiers in Australia and Papua New Guinea. Hikobia 11: 467-462.

Pócs T. 2003.Cololejeunea. In: S. R. GradsteIn \& D. P. CosTA, The Hepaticae and Anthocerotae of Brazil. Mem. New York Bot. Gard. 87: 130-135.

Pócs T. 2012. Bryophytes from Fiji Islands, VI. The genus 
Cololejeunea Raddi (Jungermanniopsida), with the description of seven new species. Acta Bot. Hung. 54(1-2): 145-188.

Pócs T. 2015. Bryophytes from the Fiji Islands, VII. Cololejeunea renneri sp. nov. (Lejeuneaceae, Marchantiophyta). Plant Science Today 2(4): 126-128.

Pócs T. \& Bernecker A. 2009. Knowledge of Aphanolejeunea (Jungermanniopsida) after 25 years. Polish Bot. J. 54(1): 1-11.

Pócs T. \& Lee G. E. 2016. Data to the Malaysian liverwort flora, II. Cryptog. Bryol. 37(1): 39-52.

Pócs T. \& Ninh T. 2005. Contribution to the bryoflora of Vietnam, VI. On the liverwort flora of Vu Quang Nature Reserve. Acta Bot. Hung. 47(1-2): 151-171.

Pócs T. \& PIIPPo S. 1999. Bryophyte flora of the Huon Peninsula, Papua New Guinea. LIV. Aphanolejeunea (Lejeuneaceae, Hepaticae). Acta Bot. Fenn. 165: 85-102.

Pócs T \& PIIPPo S. 2011. Bryophyte flora of the Huon Peninsula, Papua New Guinea. LXXIV. Cololejeunea (Lejeuneaceae, Jungermanniopsida). Acta Bryolichenol. Asiat. 4: 59-137.

Pócs T. \& Streimann H. 1999. Epiphyllous liverworts from Queensland, Australia. Bryobrothera 5: 165-172.

Pócs T. \& Streimann H. 2006. Contributions to the bryoflora of Australia, I. Trop. Bryol. 27: 19-24.

Pócs T., Bernecker A. \& Tixier P. 2014. Synopsis and key to species of Neotropical Cololejeunea (Lejeuneaceae). Acta Bot. Hung. 56(1-2): 185-226.

Pócs T., Sass-Gyarmati A., Naikatini A., Tuiwawa M., BragGINS J., Pócs S. \& von Konrat M. 2011. New liverwort (Marchantiophyta) records for the Fiji Islands. Telopea 13: 455-494.

Renner M. A. M. 2011. New records, range extensions and descriptions for some unfamiliar Australian Lejeuneaceae (Jungermanniopsida). Telopea 13(3): 563-576.

Schuster R. M. 1980. The Hepaticae and Anthocerotae of North America. Volume IV. Columbia University Press, New York.

Scotт G. A. M. 1987. Some leafy liverworts from Cape York Peninsula. Queensland Naturalist 28: 64.

Scott G. A. M. 1997. Bryophytes. In: G. A. M. Scott, T. J. Entwistle, T. W. May \& G. N. Stevens, A Conservation Overview of Australian Non-Marine Lichens, Bryophytes, Algae and Fungi, pp. 23-33 \& 106-141. Environment Australia, Canberra.

SöDerström L., Gradstein S. R. \& Hagborg A. 2010. Checklist of the hornworts and liverworts of Java. Phytotaxa 9: $53-149$.

SöDerström L., Barrie F. R., Hagborg A., Crandall-StotLer B. J., Gradstein S. R., Stotler R. E. \& von Konrat M. 2015. Notes on Early Land Plants Today. 73. Genera of
Lejeuneaceae established in the period 1884-1893: dates of validation and implications. Phytotaxa 220(2): 143-198.

SöDerström L., Hagborg A., von Konrat M., BartholomewBegan S., Bell D., Briscoe L., Brown E., Cargill D. C., Cooper E. D., Costa D. P., Crandall-Stotler B. J., Dauphin G., Engel J. J., Feldberg K., Glenny D., Gradstein S. R., He X., Heinrichs J., Hentschel J., Ilkiu-Borges A. L., Katagiri T., Konstantinova N. A., Larraín J., Long D. G., Nebel M., Pócs T., Puche F., Reiner-Drehwald E., Renner M. A. M., Sass-Gyarmati A., SchäFer-Verwimp A., Segarra Moragues J. G., Stotler R. E., Sukkharak P., Thiers B. M., Uribe J., Vaña J., Villarreal J. C., Wigginton M., Zhang L. \& ZHU R.-L. 2016. World checklist of hornworts and liverworts. PhytoKeys 59: 1-828.

ThIERs B. 1988. The Australian species of Cololejeunea. Nova Hedwigia Beih. 90: 113-146.

Thiers B. 1990. An overview of the Lejeuneaceae in Australia. Trop. Bryol. 2: 273-283.

Thiers B. M. 1997. Lejeunea bischlerae, a new species of Lejeunea subgenus Microlejeunea from Australia. Cryptog. Bryol. Lichénol. 18(3): 223-226.

Thiers B. M., SöDerström L., Hagborg A. \& von Konrat M. 2012. Notes on early land plants today. 11. Microlejeunea bischlerae (B.M. Thiers) comb. nov. Phytotaxa 65: 59.

Thouvenot L., Gradstein S. R., Hagborg A., SöDerström L. \& BARDAT J. 2011. Checklist of the liverworts and hornworts of New Caledonia. Cryptog. Bryol. 32(4): 287-390.

Tixier P. 1969. Cololejeunea de l'Asie du Sud-Est. I. - Leonidentes et espèces affines. Rev. Bryol. Lichenol. 36(3/4): 543-594.

TIXIER P. 1977. La notion d'espèce chez le genre Cololejeunea. C. schmidtii (St.) P. Tix. el les taxa voisins. Rev. Bryol. Lichénol. 43: 35-52.

TiXIER P. 1979. Contribution à l'étude du genre Cololejeunea. Les Cololejeunoidées de Nouvelle Calédonie. Essai monographique. Nova Hedwigia 31: 721-787.

TIXIER P. 1981. La notion d'espèce chez le genre Cololejeunea. Le complexe Cololejeunea floccosa (Lehm. \& Lindenb.) Schiffn. Cryptog. Bryol. Lichénol. 2(1): 47-76.

TIXIER P. 1984. Contribution à l'étude du genre Cololejeunea Le complexe Cololejeunea longifolia (Mitt.) Ben. Est-il monotypiques? Cryptog. Bryol. Lichénol. 5(1-2): 111-125.

TIXIER P. 1985. Contribution à la Connaissance des Cololejeuneoideae. Bryophyt. Biblioth. 27: 1-439.

TIXIER P. 1988. Contribution à l'étude du genre Cololejeunea (Lejeuneaceae, Hepaticae) X. Espèces nouvelles récoltées par Sten Bergman en Irian Jaya (1949). Bull. Jard. Bot. Nat. Belg. 59: 439-444.

Vanden Berghen C. 1972. Hepatiques epiphylles recoltees au Burundi par J. Lewalle. Bull. Jard. Bot. Nat. Belg. 42(4): 431-494. 
WigGinton M. J. 2009. Checklist and distribution of the liverworts and hornworts of sub-Saharan Africa, including the East African Islands (edition 3, 24 January 2009). Trop. Bryol. Res. Rep. 8: 1-116.

Wilson R., Heirichs J., Hentschel J., Gradstein S. R. \& SCHNEIDER H. 2007. Steady diversification of derived liverworts under Tertiary climatic fluctuations. Biology Letters 3: 566-569.

Windolf J. 1985a. Survey of the Hepaticae and Anthocerotae of the Sunshine Coast region, Queensland. J. Hattori Bot. Lab. 59: 171-176.

WindolF J. 1985b. Appendix 2. Checklist of the bryophytes of Mt. Coolum. Queensland Naturalist 25: 75-78.

Windolf J. 1987. Annotated list of Queensland Hepaticae. Austrobaileya 2: 380-400.

YU Y., Pócs T. \& ZHU R-L. 2014. Notes on Early Land Plants Today. 62. A synopsis of Myriocoleopsis (Lejeuneaceae, Marchantiophyta) with special reference to transfer of
Cololejeunea minutissima to Myriocoleopsis. Phytotaxa 183(4): 293-297.

Yu Y., Pócs T., Schäfer-Verwimp A., Heinrichs J., Zhu R.-L. \& Schneider H. 2013. Evidence for Rampant Homoplasy in the Phylogeny of the Epiphyllous Liverwort Genus Cololejeunea (Lejeuneaceae). Syst. Bot. 38: $553-563$.

Zanten B. O. \& Pócs T. 1981. Distribution and dispersal of bryophytes. In W. Schultze-Motel (ed.), Advances in Bryology. 1: 479-562. J. Cramer, Vaduz.

ZHU R.-L. 1995. Notes on some species of the genus Cololejeunea (Lejeuneaceae, Hepaticae) in China. J. Hattori Bot. Lab. 78: 83-109.

ZHU R.-L. \& So M. L. 1999. Additions of Lejeuneaceae taxa to the hepatic flora of Yunnan, China. Ann. Bot. Fenn. 36: 219-229.

ZHU R.-L. \& So M. L. 2001. Epiphyllous liverworts of China. Nova Hedwigia Beih. 121: 1-418. 